\title{
INFLUENCE OF THE SPATIAL DISTRIBUTION OF VEGETATION AND SOILS ON THE PREDICTION OF CUMULUS CONVECTIVE RAINFALL
}

\author{
Roger A. Pielke Sr. \\ Department of Atmospheric Science \\ Colorado State University \\ Fort Collins, Colorado
}

\begin{abstract}
This paper uses published work to demonstrate the link between surface moisture and heat fluxes and cumulus convective rainfall. The Earth's surface role with respect to the surface energy and moisture budgets is examined. Changes in land-surface properties are shown to influence the heat and moisture fluxes within the planetary boundary layer, convective available potential energy, and other measures of the deep cumulus cloud activity. The spatial structure of the surface heating, as influenced by landscape patterning, produces
\end{abstract}

focused regions for deep cumulonimbus convection. In the tropics, and during midlatitude summers, deep cumulus convection has apparently been significantly altered as a result of landscape changes. These alterations in cumulus convection teleconnect to higher latitudes, which significantly alters the weather in those regions. The effect of tropical deforestation is most clearly defined in the winter hemisphere. In the context of climate, landscape processes are shown to be as much a part of the climate system as are atmospheric processes.

\section{INTRODUCTION}

The fuel for thunderstorms is heat energy. This heat energy can be derived from sensible heating at the Earth's surface and from the release of heat as water vapor condenses or freezes. To develop into the characteristic cauliflower form of a thunderstorm cloud, the cloud air must be warmer than the surrounding air, such that the cloud air accelerates upward in a turbulent, bubbly form. The cauliflower-shaped cloud terminates its upward ascent at strong temperature inversions in the troposphere or, more commonly, at the tropopause, which separates the troposphere from the stratosphere. The cloud material at this level then spreads out horizontally in the characteristic anvil shape of a thunderstorm. Electrification, as different sized ice particles collide within the turbulent cloud and transfer electric charge, is what produces the lightning that gives the name to these clouds. Thunderstorms are also called "electrical storms." The technical name for a thunderstorm cloud is a "cumulonimbus cloud."

There are several review sources that overview thunderstorms and organized clusters of thunderstorms. These include Cotton [1990], Cotton and Anthes [1989], Houze [1993], and Pielke and Pielke [1999]. Review material on the boundary layer, which is the link between the landscape and deep cumulus convection, is given by Holtslag and Duynkerke [1998], Stull [1988], Oke [1987],
Arya [1988], Garstang and Fitzjarrald [1999], Garratt [1992], and Sorbjan [1989].

The interaction between the Earth's surface and the atmosphere is therefore critically important with respect to the development of cumulus convective rainfall. Weather forecasters use a variety of parameters, derived from the vertical profile of thermodynamic variables in the atmosphere, to assess the potential for such rainfall. These parameters are introduced in Appendix A and will be referred to within the text.

\subsection{Surface Effects}

The surface energy and moisture budgets for bare and vegetated soils during typical thunderstorm weather conditions (snow and ice effects are not considered in this discussion) are schematically illustrated in Figures 1 and 2. These surface budgets can be written as

$$
\begin{gathered}
R_{N}=Q_{G}+H+L(E+T) \\
P=E+T+R O+I,
\end{gathered}
$$

where $R_{N}$ represents the net radiative fluxes $=Q_{s}(1-$ $A)+Q_{L W}^{\downarrow}-Q_{L W}^{\uparrow} ; P$ is the precipitation; $E$ is evaporation (this term represents the conversion of liquid water into water vapor by nonbiophysical processes, such as from the soil surface and from the surfaces of leaves and branches); $T$ is transpiration (which represents the phase conversion to water vapor, by biological processes, through stoma on plants); $Q_{G}$ is the soil heat flux; $H$ is 
(a)

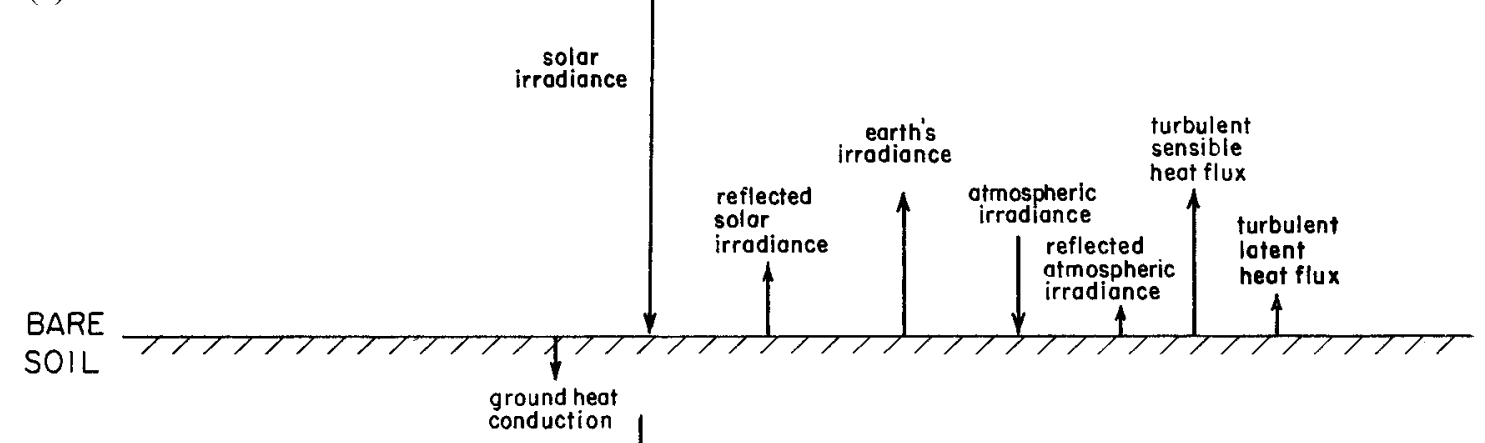

(b)

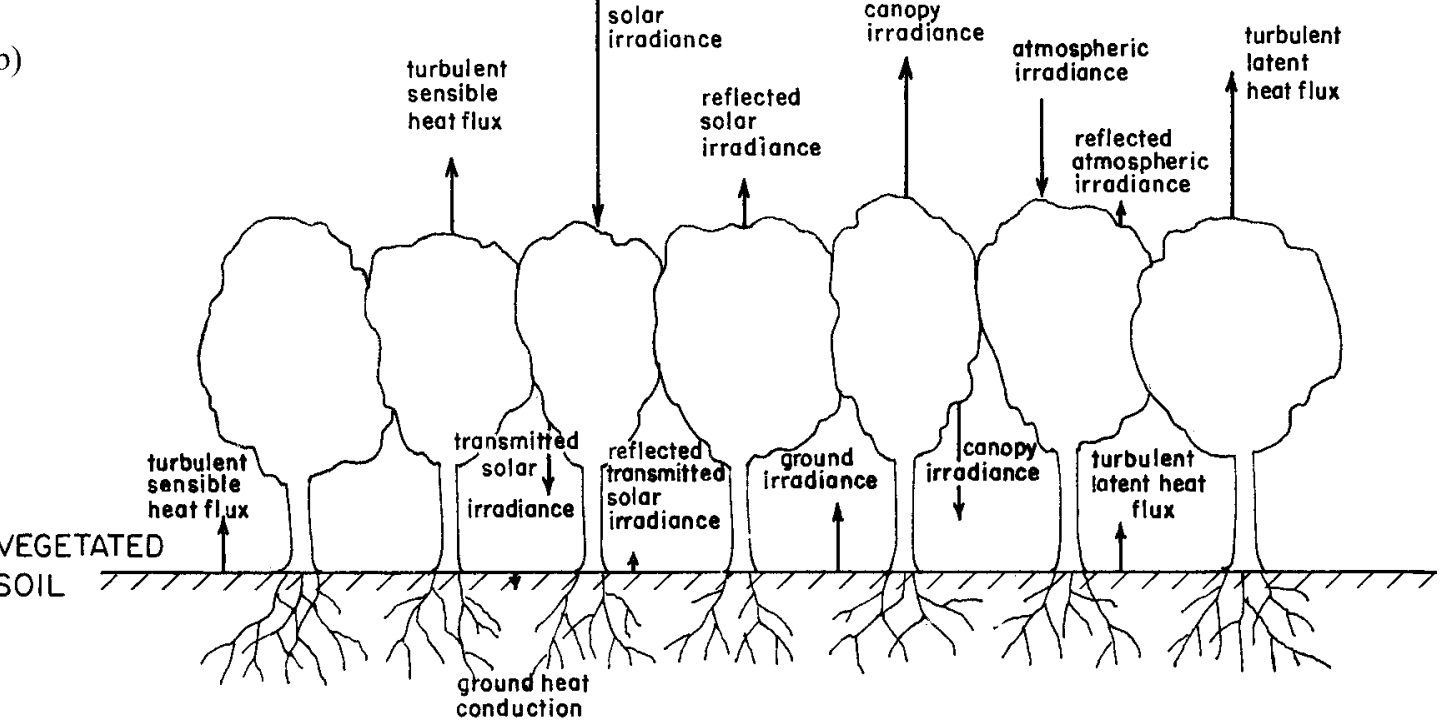

Figure 1. Schematic illustration of the surface heat budget over (a) bare soil and (b) vegetated land. The roughness of the surfaces (and for the vegetation, its displacement height) will influence the magnitude of the heat flux. Dew and frost formation and removal will also influence the heat budget. Adapted from Pielke and Avissar [1990] with kind permission from Kluwer Academic Publishers.

the turbulent sensible heat flux; $L(E+T)$ is the turbulent latent heat flux; $L$ is the latent heat of vaporization; $R O$ is runoff; $I$ is infiltration; $Q_{s}$ is insolation; $A$ is albedo; $Q_{L W}^{\downarrow}$ is downwelling longwave radiation; $Q_{L W}^{\uparrow}$ is upwelling longwave radiation $=(1-\varepsilon) Q_{L W}^{\downarrow}+\varepsilon \sigma T_{s}^{4}$; $\varepsilon$ is the surface emissivity; and $T_{s}$ is the surface temperature.

Detailed discussion of these terms is given by Pielke [1984, chapter 11]. Equations (1) and (2) are not independent of each other. A reduction in evaporation and transpiration in (2), for example, increases $Q_{G}$ and/or $H$ in (1) when $R_{N}$ does not change. This reduction can occur, for example, if runoff is increased (such as through clear-cutting a forest). The precipitation rate, and type, also obviously influence how water is distributed between runoff, infiltration, and the interception of water on plant surfaces.

The relative amounts of turbulent sensible $(H)$ and latent heat fluxes $[L(E+T)]$ are used to define the quantity called the Bowen ratio $(B)$ and the evaporative fraction $e_{f}$;

$$
B=\frac{H}{L(E+T)} ; \quad e_{f}=L(E+T) / R_{N} .
$$

The denominator $L(E+T)$ has been called "evapotranspiration," although since evaporation and transpiration involve two distinct pathways for liquid water to convert to water vapor, the use of the term "evapotranspiration" should be discouraged. The relation of $R_{N}$ to $H$ and $L(E+T)$, following Segal et al. [1988], can be written as

$$
H \cong \frac{R_{N}-Q_{G}}{(1 / B)+1}
$$

With $Q_{G} \ll H$ and $E+T$, as discussed by Segal et al. [1988],

$$
H \cong\left(\frac{1+B}{B}\right) R_{N}
$$



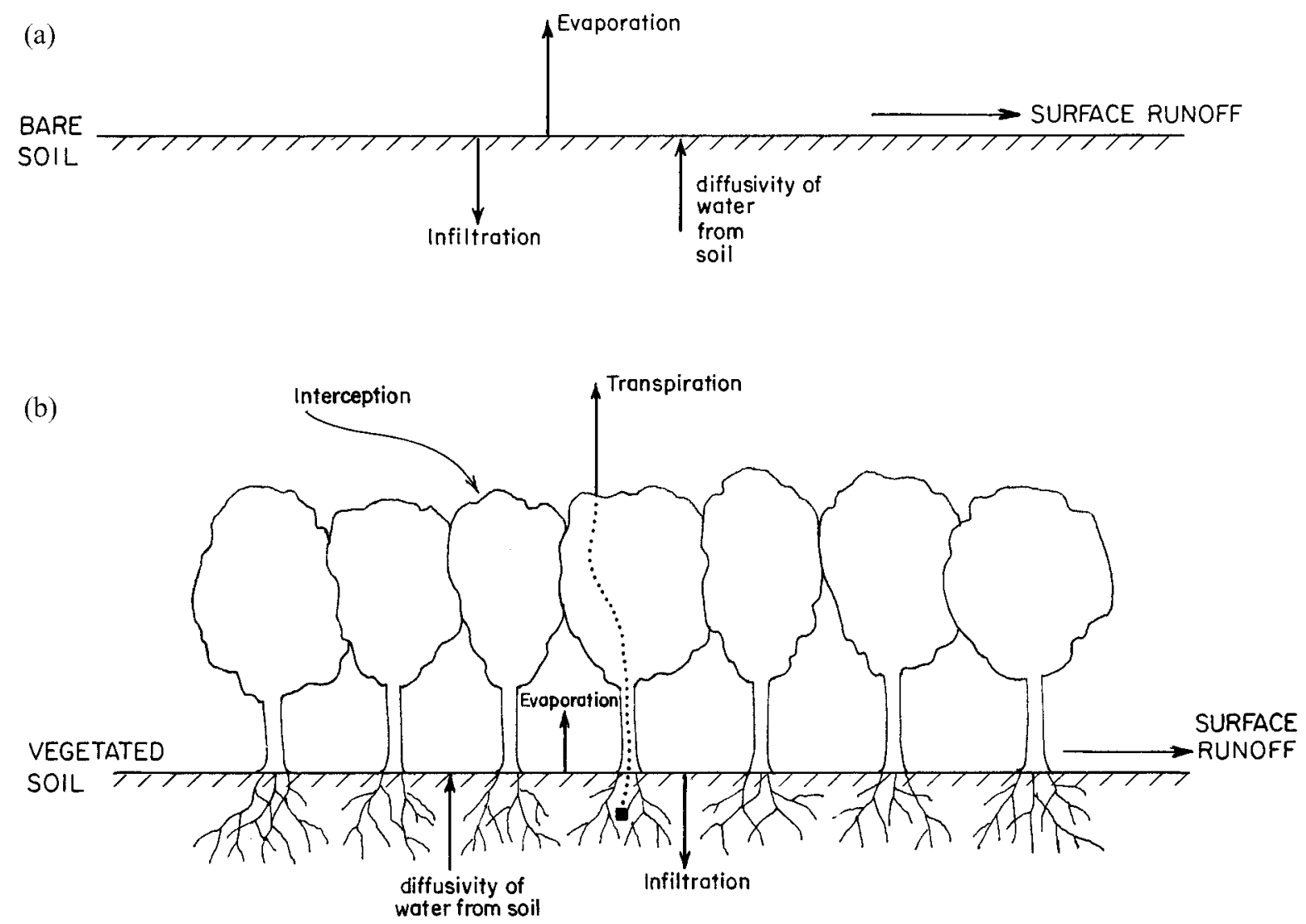

Figure 2. Schematic illustration of the surface moisture budget over (a) bare soil and (b) vegetated land. The roughness of the surface (and for the vegetation, its displacement height) will influence the magnitude of the moisture flux. Dew and frost formation and removal will also influence the moisture budget. Adapted from Pielke and Avissar [1990] with kind permission from Kluwer Academic Publishers.

Segal et al. [1995] showed that with the same value of $R_{N}$, with a smaller Bowen ratio, the thermodynamic potential for deep cumulus convection increases.

Therefore any land use change that alters one or more of the variables in (1) and (2) will directly affect the potential for thunderstorms, and their resultant intensity, if they occur. For instance, a decrease in $A$ (i.e., a darkening of the surface) would increase $R_{N}$, thus making more heat energy available for $Q_{G}, H, E$, and $T$. The heat that goes into $H$ increases $\theta$ because temperature increases (see the formula for $\theta$ following equation (A2); note that $T$ is used for both transpiration and temperature, where the context in which $T$ is used will indicate which quantity it refers to). The heat that goes into $E$ or $T$ goes into $\theta_{e}$ because $w$ increases (see equation (A14)). If the surface were dry and bare, all of the heat energy would necessarily go into $Q_{G}$ and $H$, as shown by Pielke [1984, p. 381] for the empty quarter in Saudi Arabia.

Lyons et al. [1996], for example, found a reduction of $H$ in southwestern Australia as a result of the conversion of land to agriculture. Bryant et al. [1990] found higher sensible heat fluxes in the Sonoran Desert of Mexico due to overgrazing. Fitzjarrald et al. [2001] and Schwartz [1994] found that the leafing out of vegetation in the spring has a dramatic effect on a reduction in $H$. Schrieber et al. [1996] and Rabin et al. [1990] discuss how cumulus cloud base height is directly related to surface heat and moisture fluxes, as modulated by the characteristics of the underlying heterogeneous surface. As discussed in Appendix A, changes in $\theta$ and $\theta_{e}$ change convective available potential energy (CAPE) and the other convective indices.

A conclusion of this analysis is that changes in the Earth's surface can result in significant changes in the surface energy and moisture budgets. These changes will influence the heat and moisture fluxes within the planetary boundary layer, CAPE, and other measures of the deep cumulus cloud activity. Section 3 of this paper presents examples of alterations in (1) and (2) and their subsequent effect on the cumulus convective indices.

\subsection{Boundary-Layer Effects}

Once the surface energy budget is altered, fluxes of heat, moisture, and momentum within the planetary boundary layer are directly affected [Segal et al., 1989]. As an example, Figure 3 illustrates an idealization of the vertical structure of the convective boundary layer, where the surface heat flux $H$, depth of the layer $z_{i}$, and the temperature stratification just above $z_{i}$ determine 

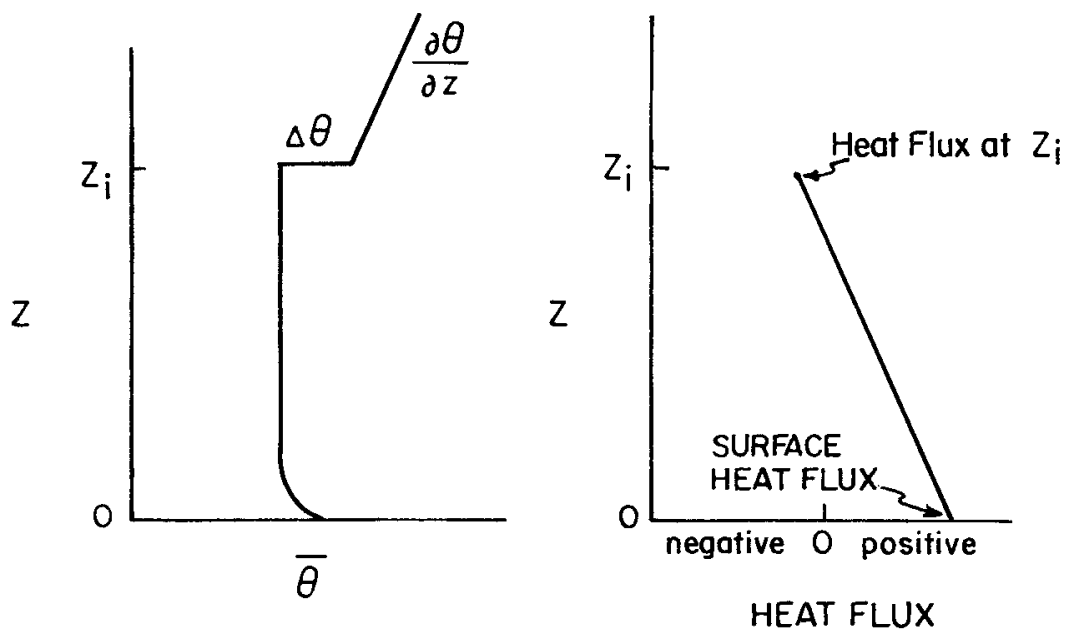

Figure 3. The potential temperature and heat flux profiles assumed in the "jump" model. Reprinted from Pielke [1984] with permission from Academic Press.

the vertical profile of temperature and heat flux. Deardorff [1974] suggested a growth rate equation for $z_{i}$, in the absence of large-scale wind flow, which is proportional to

$$
\frac{\partial z_{i}}{\partial t} \sim H^{2 / 3} z_{i}^{-4 / 3}
$$

The entrainment of air from above $z_{i}$ to heights below $z_{i}$ is given by

$$
H_{z_{i}}=-\alpha H
$$

where $\alpha$ is the entrainment coefficient $(\alpha \cong 0.2$, although there are suggestions it is different from this value [Betts et al., 1992]). McNider and Kopp [1990] discuss how the size of thermals generated from surface heating are a function of $z_{i}, H$, and height within the boundary layer. The rate of growth of the boundary layer during the day, and the ingestion of free atmospheric air into the boundary layer, are therefore both dependent on the surface heat flux $H$.

A simplified form of the prognostic equation for $\theta$ can be used to illustrate how temperature change is related to the surface heat flux $H_{s}$,

$$
\frac{\partial \theta}{\partial t}=\frac{\partial}{\partial z}\left(\frac{H}{\rho C_{p}}\right),
$$

where $\rho$ is the air density and $C_{p}$ is the specific heat at constant pressure. Integrating from the surface to $z_{i}$ and using the mean value theorem of calculus yields

$$
\frac{\partial \bar{\theta}}{\partial t}=\frac{1}{z_{i} \rho C_{p}}\left[H_{s}-H_{z_{i}}\right]=\frac{1.2}{\rho C_{p} z_{i}} H_{s},
$$

where (4b) with $\alpha=1.2$ has been used. Using this equation, a heating rate of a $1-\mathrm{km}$-deep boundary layer of $2^{\circ} \mathrm{C}$ over 6 hours is produced by a surface heat flux of $100 \mathrm{~W} \mathrm{~m}^{-2}$.
Figures 4 and 5 show how $H$, and therefore other characteristics of the boundary layer, including $z_{i}$, as based on actual observations, are altered as a result of different land-surface characteristics. Segal et al. [1989] discuss how wet soils and canopy temperatures affect the growth of the boundary layer. Amiro et al. [1999] measured elevations of surface radiometric temperatures by up to $6^{\circ} \mathrm{C}$, which remained elevated even for 15 years, after forest fires in the Canadian boreal forest. The conclusion from the analyses in this section, and the associated references, is that the boundary layer structure, including its depth, are directly influenced by the surface heat and moisture fluxes.

\subsection{Local Wind Circulations}

Local wind circulations can subsequently result from horizontal variations in $H$ and $z_{i}$ [Segal and Arritt, 1992]. Such wind circulations are referred to as "solenoidal circulations" and are the reason sea and land breezes occur [Simpson, 1994; Pielke, 1984, chapter 13]. The reason that these local wind circulations can develop is described in Appendix A, based on the work of Pielke and Segal [1986].

Of particular importance of mesoscale circulations to deep cumulus convection is the production of focused regions of particularly favorable conditions [Pielke et al., 1991b]. In these areas, CAPE and other measures of the potential for deep cumulus convection are increased in response to boundary wind convergence associated with the local wind circulations [Pielke et al., 1991a]. Convective inhibition is reduced in these areas. These wind convergence zones can also provide specific vertical motion "triggers" with which to initiate deep cumulus convection. Therefore the spatial structure of the surface heating, as influenced by landscape, can produce focused regions for deep cumulonimbus convection. 


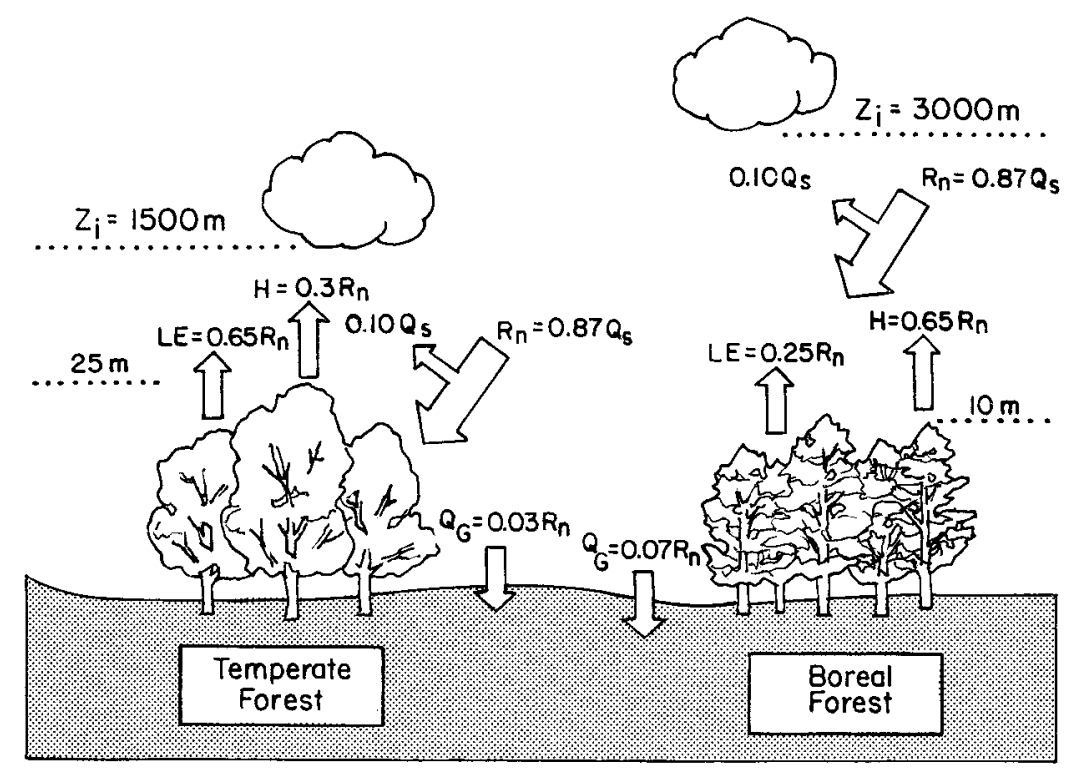

Figure 4. Schematic of the differences in surface heat energy budget and planetary boundary layer over a temperate forest and a boreal forest. The symbols used refer to equation (1). Horizontal fluxes of heat and heat storage by vegetation are left out of the figure. Adapted from P. Kabat (personal communication, 1999). Reprinted with permission.

\section{VERTICAL PERSPECTIVE}

As overviewed in section 1, any aspects of landsurface characteristics which influence the heating and moistening of the atmospheric boundary layer will affect the potential for cumulus convective rainfall. Therefore vertical radiosonde soundings over adjacent locations that have different surface conditions offer opportunities to assess alterations in thunderstorm potential. This influence of surface conditions on cumulus cloud and thunderstorm development has been discussed, for ex- ample, by Clark and Arritt [1995], Crook [1996], Cutrim et al. [1995], Garrett [1982], and Hong et al. [1995].

Figure 6 illustrates two soundings made over two locations in northeastern Colorado at 1213 local standard time (LST) on July 28, 1987 [Segal et al., 1989; Pielke and Zeng, 1989]. The soundings were made prior to significant cloud development. The radiosonde sounding over an irrigated location had a slightly cooler but moister lower troposphere than the sounding over the natural, short-grass prairie location. Aircraft flights at several levels between these two locations on July 28,
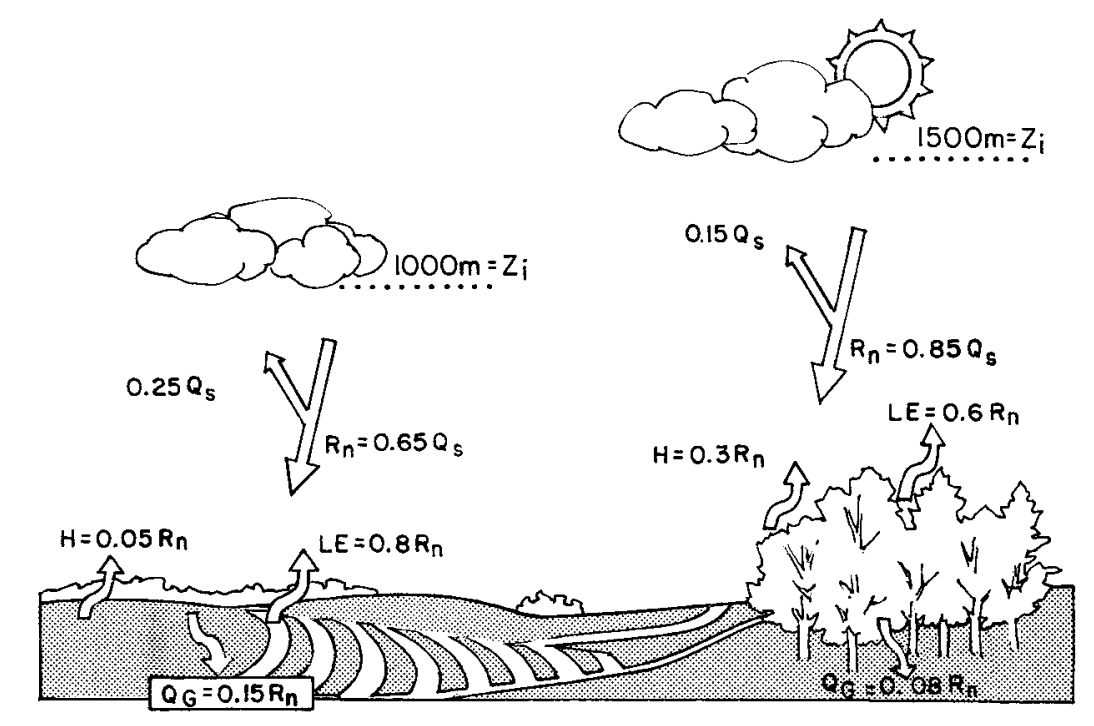

Figure 5. Same as Figure 4 except between a forest and cropland. Adapted from P. Kabat (personal communication, 1999). Reprinted with permission. 


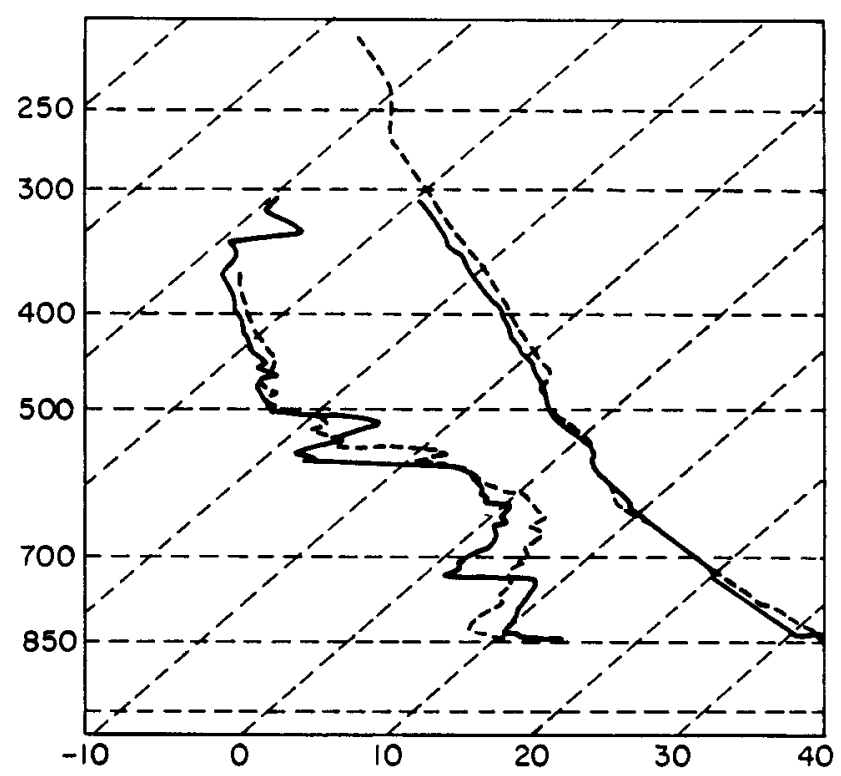

Figure 6. Radiosonde measurements of (right) temperature and (left) dew point temperature for a dry land area (dashed curve) and an irrigated area (solid curve) in northeast Colorado at 1213 local standard time (LST) on July 28, 1987. Reprinted from Pielke and Zeng [1989] with permission from National Weather Association.

1987 (Figures 7 and 8), demonstrate that the moistening and cooling occurred over the entire region of irrigation. Using a convective index described in Appendix A, the lifted index, assuming surface parcel ascent, was -2 over the irrigated land but zero over the short-grass prairie [Pielke and Zeng, 1989]. For this case, the moistening of the lower atmosphere over the irrigated area was more important in increasing CAPE than was the slight cooling in decreasing CAPE.

U. Nair and R. Welch (personal communication, 1999) have completed a study to assess the alteration to CAPE over the United States if a $1{ }^{\circ} \mathrm{C}$ increase or decrease to the surface dew point temperature or the air temperature were to occur. The climatological average values of CAPE, derived from radiosonde analyses, are shown in Figure 9a. Figure 9b shows the change in CAPE with a $1^{\circ} \mathrm{C}$ increase in dew point temperature. The sensitivity calculation produced large increases in CAPE in portions of the United States, particularly in the southern United States, where the climatological amount of water vapor is already high. The increase of $1^{\circ} \mathrm{C}$ in air temperature had a much smaller impact on CAPE (Figure 9c). This analysis clearly shows the very large sensitivity of cumulus convective rainfall to the land-surface energy and moisture budgets, particularly in humid areas.

The use of the concept of moist static energy,

$$
S=C_{p} T+L q+g z,
$$

can provide an additional demonstration of the role of moisture increase on CAPE. $S$ is essentially the same as $\theta_{e}$, the equivalent potential temperature derived in Appendix A. If we assume $z$ is unchanged, we can express the relation between a change of dew point temperature (as represented by $q$ ) and what change in $T$ would have to occur to produce the same change in $S$; i.e.,

$$
\delta T=\frac{L}{C_{p}} \delta q
$$

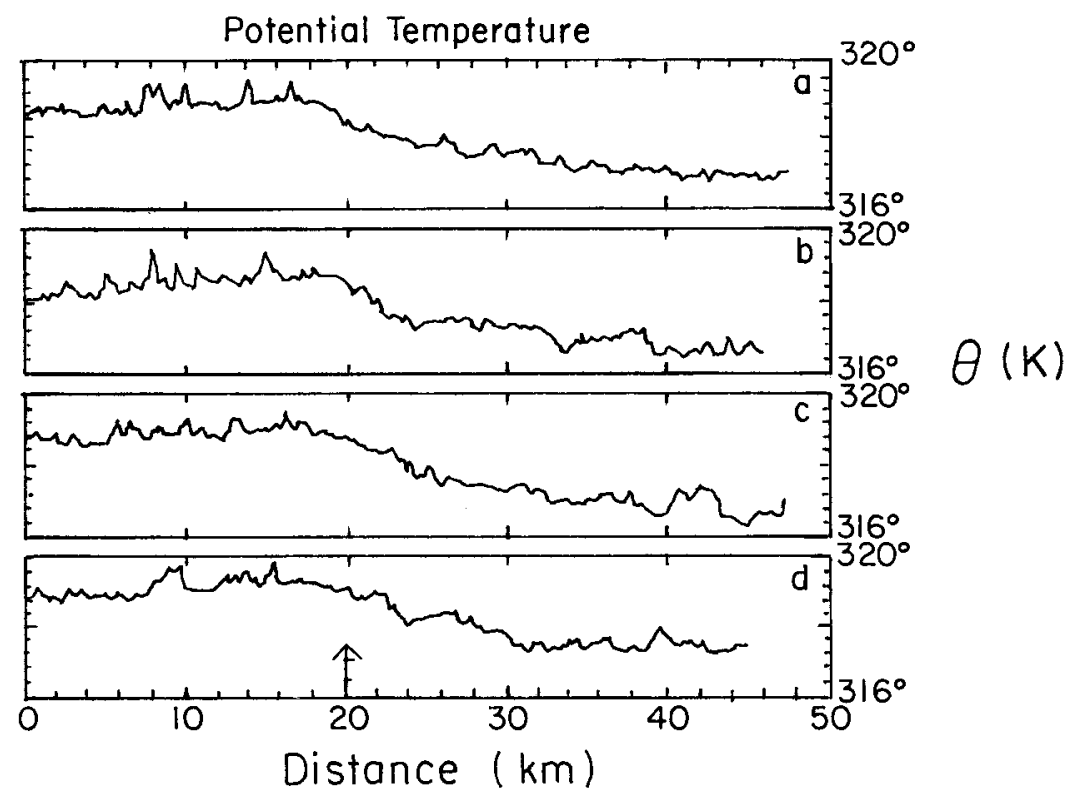

Figure 7. Measured potential temperature from Briggsdale to Windsor at the altitude of (a) $140 \mathrm{~m}$, (b) $240 \mathrm{~m}$, (c) $345 \mathrm{~m}$, and (d) $440 \mathrm{~m}$ above the ground. The observed crop-dry land boundary is indicated by an arrow, with cropland to its right. Adapted from Segal et al. [1989] with permission from American Meteorological Society. 
Mixing Ratio

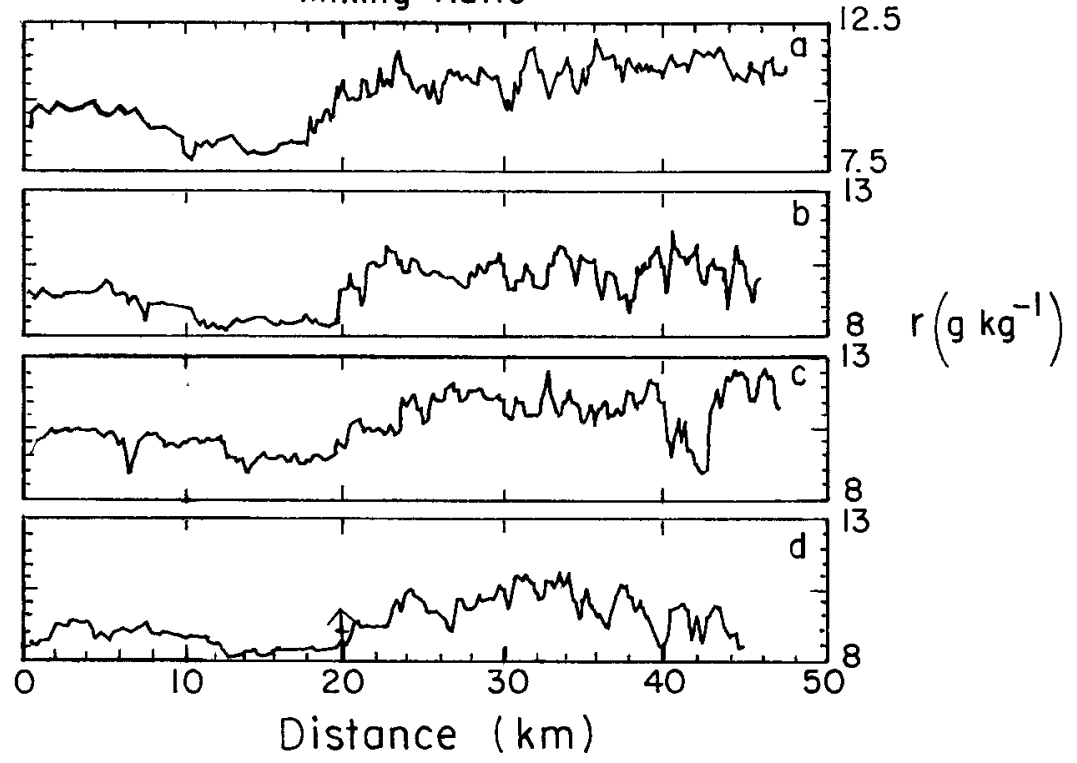

Figure 8. Same as Figure 7 except for moisture mixing ratio. Adapted from Segal et al. [1989] with permission from American Meteorological Society.

A $1^{\circ} \mathrm{C}$ change in dew point temperature from $23^{\circ} \mathrm{C}$ to $24^{\circ} \mathrm{C}$ at 1000 mbar (which changes $q$ from $\sim 18$ to $\sim 19 \mathrm{~g}$ $\mathrm{kg}^{-1}$ ), for example, produces a $2.5^{\circ} \mathrm{C}$ change in $\delta T$ in (6). In other words, with the temperatures used here, the air temperature would have to increase by $2.5^{\circ} \mathrm{C}$ to produce the same change in moist static energy as a $1^{\circ} \mathrm{C}$ increase in dew point temperature. With a cooler atmosphere, a dew point temperature increase of $1^{\circ} \mathrm{C}$ would have a smaller effect, while a warmer atmosphere would produce a greater effect. De Ridder [1997] and Segal et al. [1995] also discuss how evaporation works to increase the equivalent potential temperature, except for very dry atmospheres. De Ridder

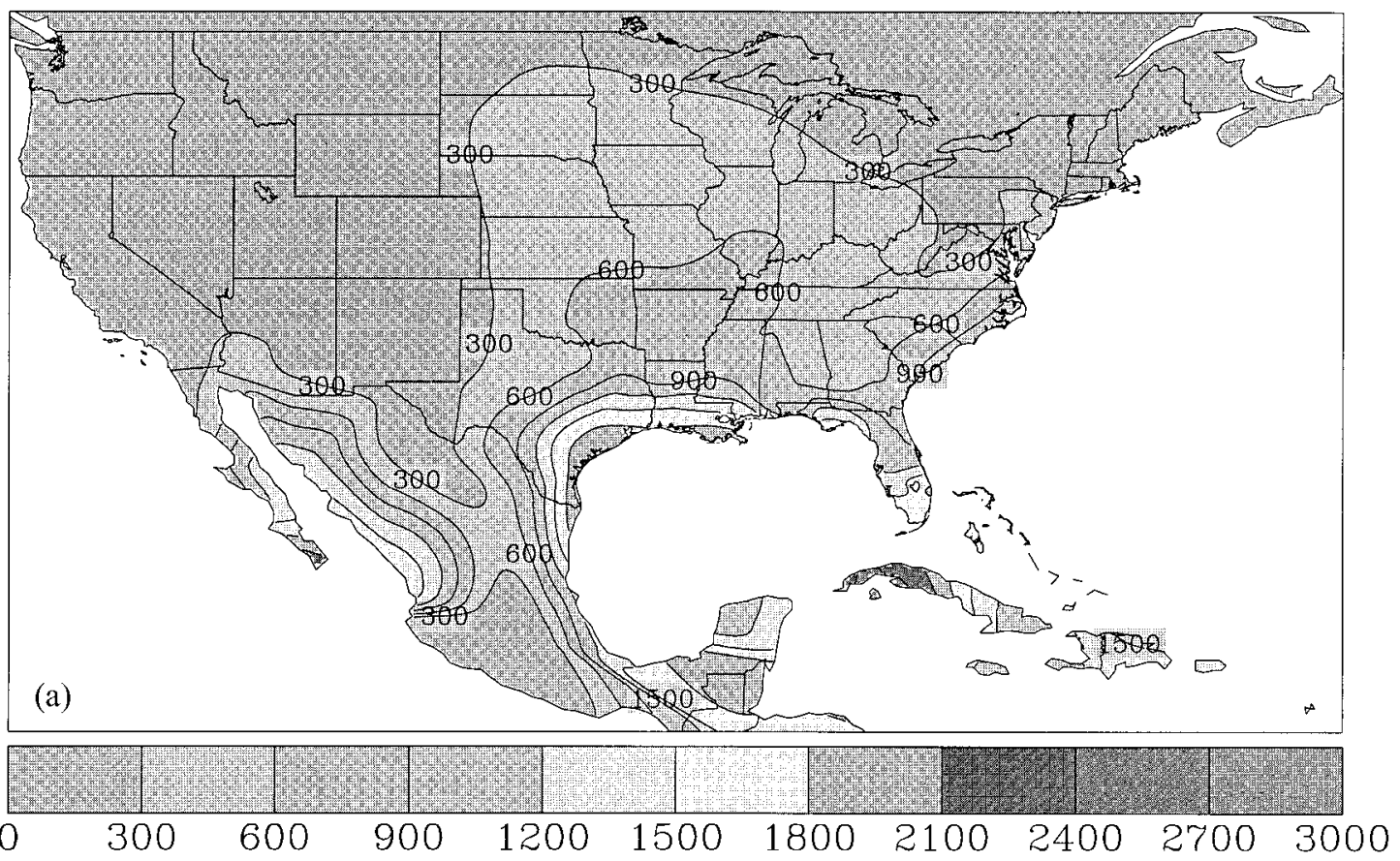

Figure 9. (a) Mean July convective available potential energy (CAPE) $\left(\mathrm{J} \mathrm{kg}^{-1}\right)$ for North America derived from 1200 UT rawinsonde observations, (b) with an added perturbation of $+1^{\circ} \mathrm{C}$ to the dew point temperature, and (c) with an added perturbation of $+1^{\circ} \mathrm{C}$ to the surface layer temperature. From U. Nair and R. Welch (personal communication, 2000). Reprinted with permission. 

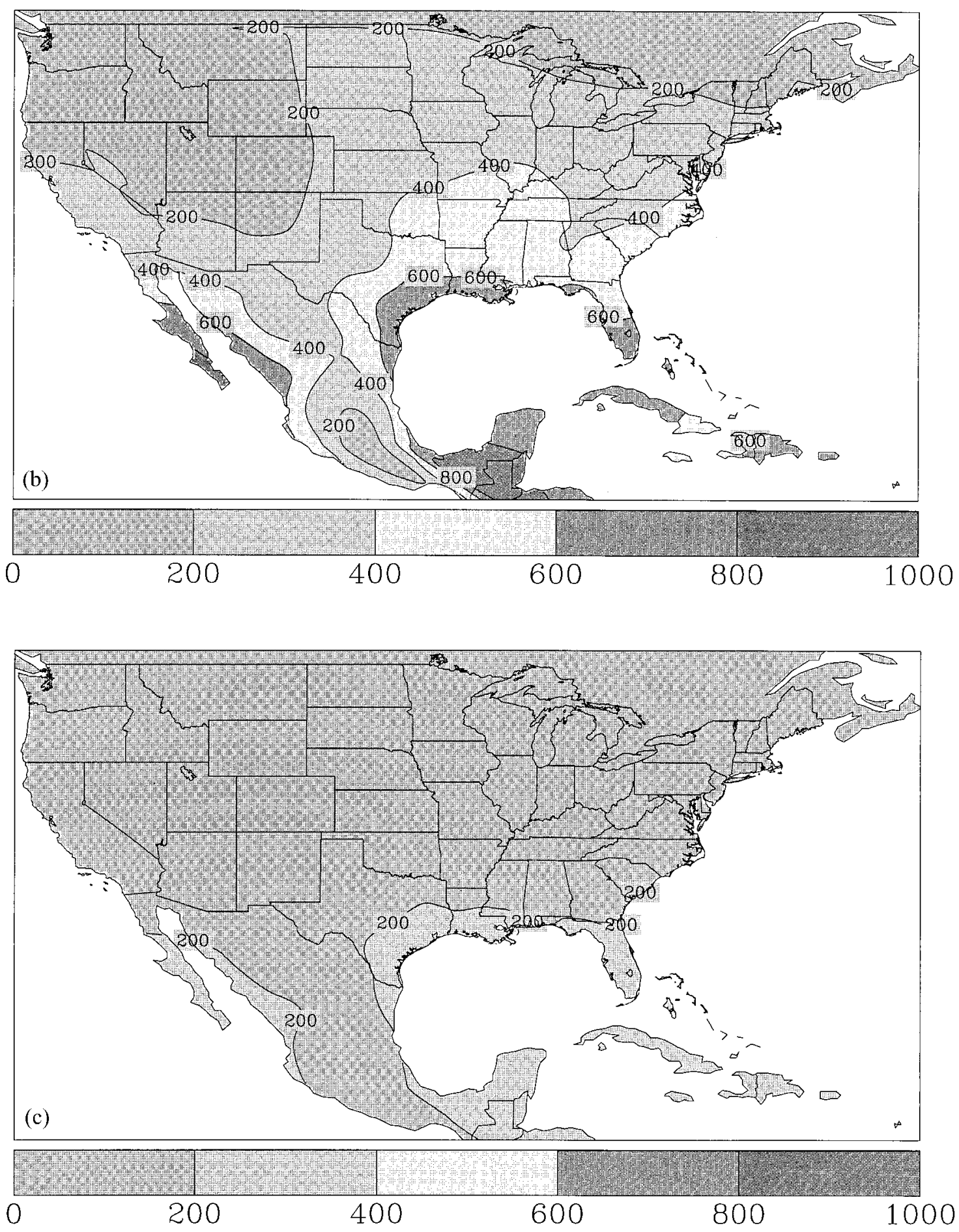

Figure 9. (continued)

and Gallée [1998], for example, found that convective rain in southern Israel has increased by a factor of 3 in October as a result of irrigation. Crook [1996] also discusses how such relatively small changes in the dew point temperature can have a large effect on cumulus convective potential. In a classic study, Barnston and Schickedanz [1984] showed how irrigation increased warm-season rain in the southern Great Plains. Lanicci et al. [1987] also investigated soil moisture effects on thunderstorms in this region.

\section{MESOSCALE AND REGIONAL HORIZONTAL PERSPECTIVE}

Since different landscape characteristics result in varying values of boundary-layer structure, mesoscale atmospheric circulations can result from the landscape heterogeneity as discussed in section 1.3. Studies of this mesoscale effect include those by Ookouchi et al. [1984], Mahfouf et al. [1987], Segal et al. [1988], Pielke et al. 


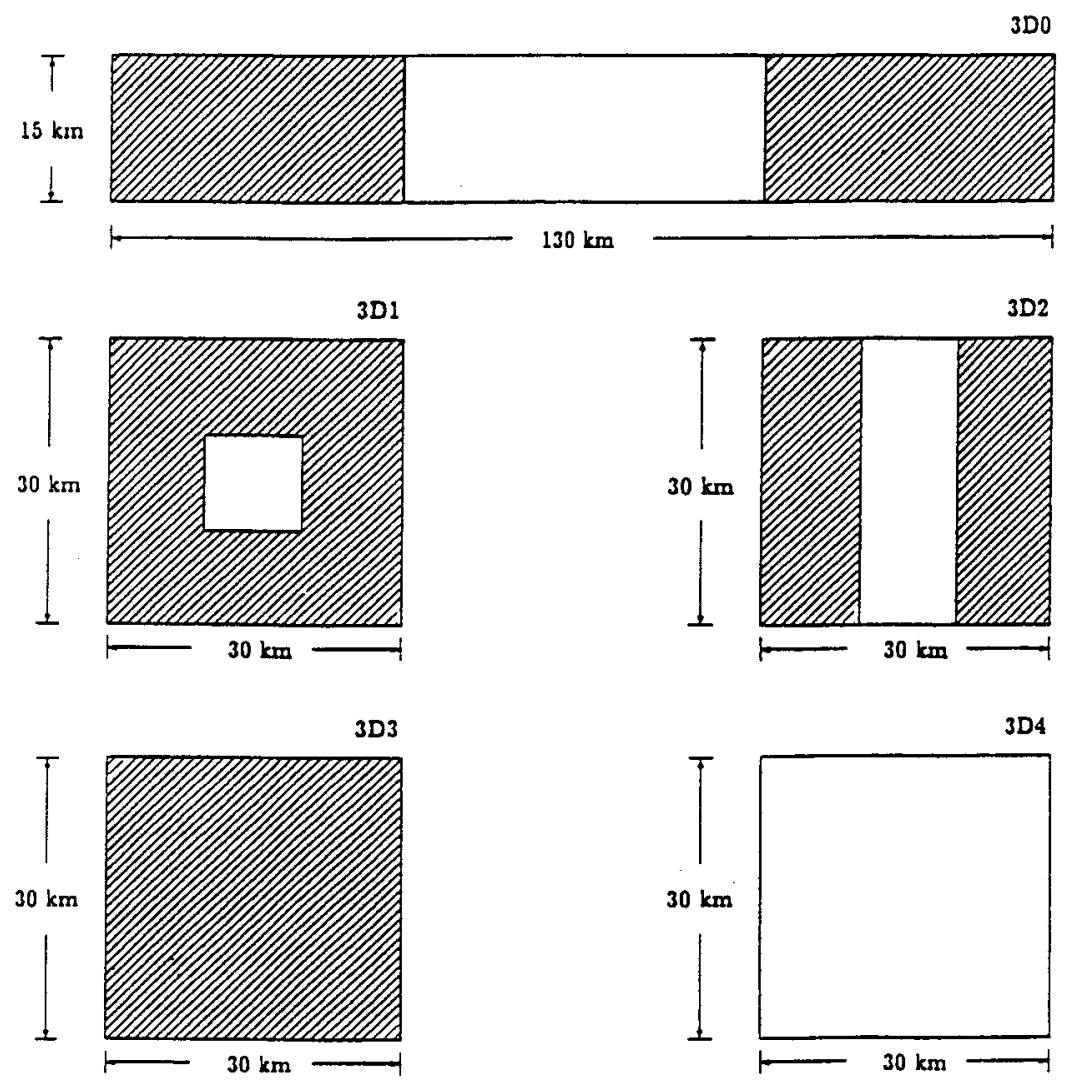

Figure 10. Schematic representation of the simulated three-dimensional domains. From Avissar and Liu [1996].

[1991b], Segal and Arritt [1992], Avissar and Chen [1993], Chen and Avissar [1994a], Goutorbe et al. [1994], Mahrt et al. [1994], Lynn et al. [1995a], Avissar and Liu [1996], Stohlgren et al. [1998], Taylor et al. [1998], Wang et al. [1997, 1998], and Chase et al. [1999]. At least one study, however, has found no significant effect, in general, due to real-world landscape heterogeneities [Zhong and Doran, 1998; Doran and Zhong, 2000]. The conclusion of this latter work is disagreed with by Weaver and Avissar [2001], where they document observationally and using the same model as applied by Zhong and Doran that landscape heterogeneity in Oklahoma and Kansas does produce organized areas of cumulus convection.

Since land-water contrasts permit the development of sea breezes, which focus thunderstorm development over islands and coastal regions in the humid tropics and in humid middle and high latitudes during the summer [e.g., see Pielke, 1984, Figure 12-13], it would be expected that similar variations in surface heating associated with landscape patterns would also produce mesoscale circulations of a similar magnitude. Other papers which describe the influence of sea breezes on thunderstorms are those by Pielke [1974] and Pielke et al. [1991b].

Avissar and Schmidt [1998] have explored how landscape patchiness influences cumulus development using a large eddy simulation. They found preferential locations within the heterogeneous landscape where pockets of relatively high moisture concentrations occurred. As shown in Figures 10 and 11, the shape of the heterogeneity strongly influences the ability of mesoscale flows to concentrate CAPE within local regions so as to permit a greater likelihood of stronger thunderstorms. The large square-shaped area, for example, is able to focus the lower tropospheric winds so as to optimize the accumulation of CAPE. This focusing of CAPE is analogous to what occurs with round islands [Neumann and Mahrer, 1974]. Dalu et al. [1996] used a linear model to conclude that the Rossby radius defined in (A41) is the optimal spatial scale for landscape heterogeneities to produce mesoscale flows. Avissar and Pielke [1989], Hadfield et al. [1991], Shen and Leclerc [1995], Zeng and Pielke [1995a, 1995b], Wang et al. [1997], and Avissar and Schmidt [1998] also explored the issue of the size of landscape patchiness that is needed before the boundary-layer structure is significantly affected and a mesoscale circulation is produced. Consistent with these conclusions, Segal et al. [1997] found that cumulus clouds are a minimum downwind of mesoscale-sized lakes during the warm season as a result of mesoscale-induced subsidence over the lake and the resultant suppression of $z_{i}$.

Other studies that have explored the influence of landscape heterogeneity on cumulus convection include those by Segal et al. [1989], Rabin et al. [1990], Chang and Wetzel [1991], Fast and McCorcle [1991], Segal and Arritt 

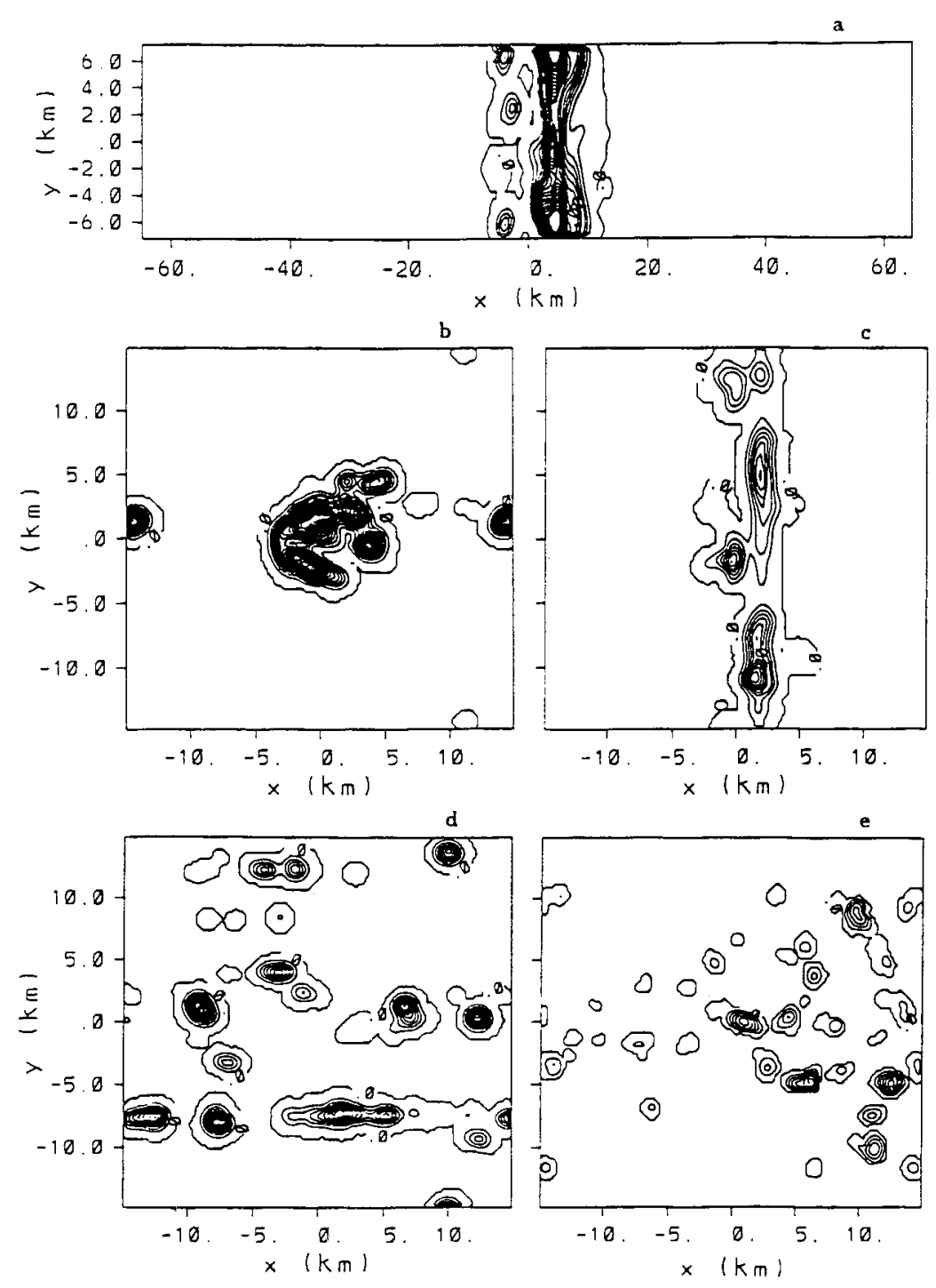

Figure 11. Accumulated precipitation (millimeters) at 1800 LST in domain (a) 3D0, (b) 3D1, (c) 3D2, (d) 3D3, and (e) 3D4. Contour intervals are $2 \mathrm{~mm}$ in 3D0, $1 \mathrm{~mm}$ in 3D1, 3D2, and 3D3, and $0.05 \mathrm{~mm}$ in 3D4. From Avissar and Liu [1996].

[1992], Chen and Avissar [1994a, 1994b], Li and Avissar [1994], Clark and Arritt [1995], Cutrim et al. [1995], Lynn et al. [1995a, 1995b, 1998], Rabin and Martin [1996], and Wang et al. [2000].

Pielke et al. [1997] present a sensitivity experiment to evaluate the importance of land-surface conditions on thunderstorm development. Using identical lateral boundary and initial values, two model simulations for May 15, 1991, were performed for the Oklahoma-Texas Panhandle region. One experiment used the current landscape (which includes irrigated crops, shrubs, as well as the natural short-grass prairie), while the second experiment used the natural landscape in this region (the short-grass prairie). Figure 12 provides the results at 1500 LST for both experiments. The simulation with the current landscape (Figure 12a) produced a thunderstorm system along the dry line, while only a shallow line of cumulus clouds was produced using the natural land- scape (Figure 12b). A thunderstorm was observed in this region on May 15, 1991, with the other meteorological quantities also realistically simulated [Grasso, 1996; Shaw et al., 1997; Ziegler et al., 1997]. The thunderstorm developed when the current landscape was used, since the enhanced vegetation coverage (higher leaf area) permitted more transpiration of water vapor into the air than would have occurred with the natural landscape. The result was higher CAPE with the current landscape.

Lyons et al. [1993, 1996] and Huang et al. [1995], in a contrasting result, found that the replacement of native vegetation with agriculture reduced sensible heat flux, with a resultant decrease in rainfall. Wetzel et al. [1996], in a study in the Oklahoma area, found that cumulus clouds form first over hotter, more sparsely vegetated areas. Over areas covered with deciduous forest, clouds were observed to form 1-2 hours later due to the suppression of vertical mixing. Rabin et al. [1990] also found 

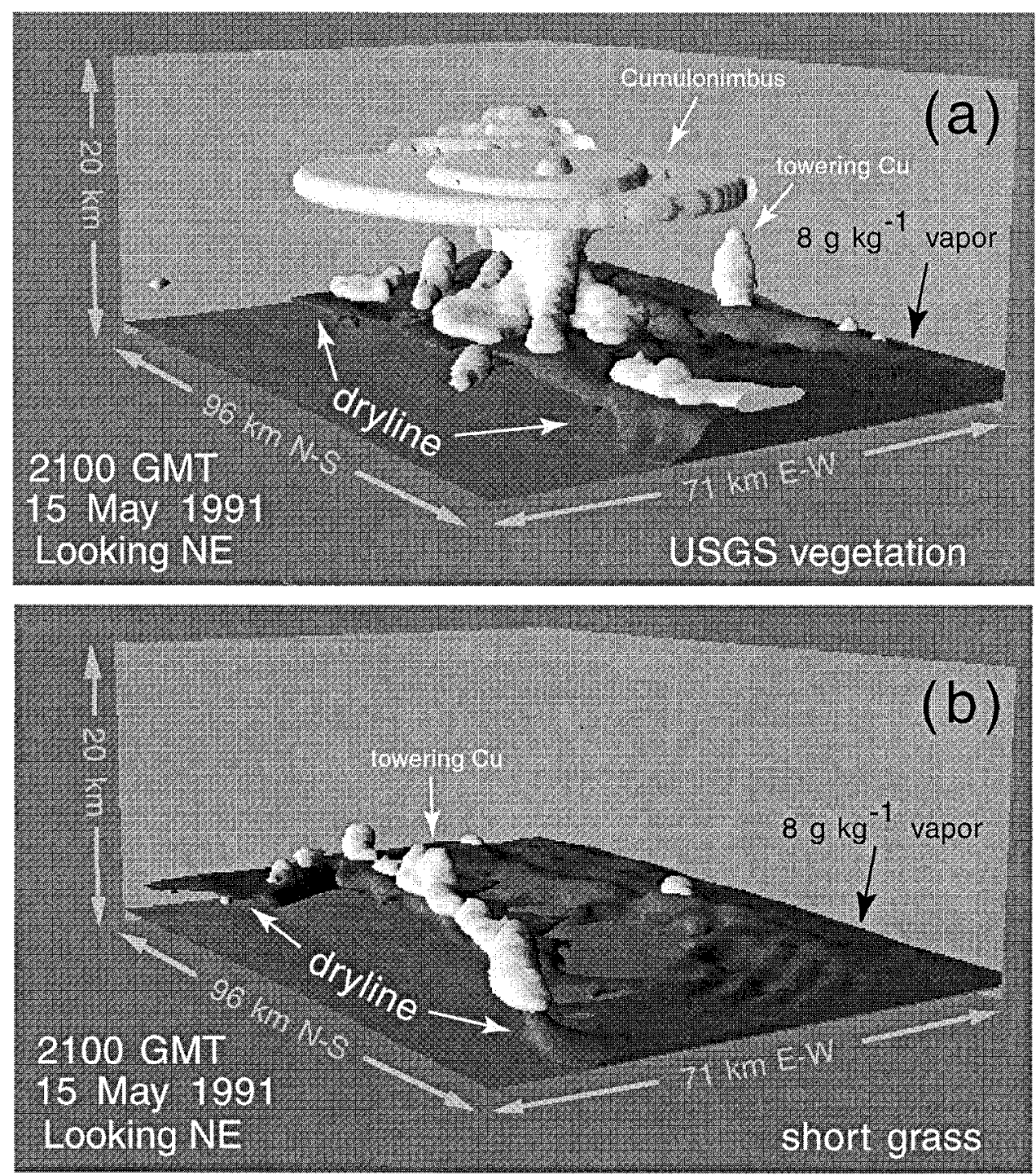

Figure 12. Model output cloud and water vapor mixing ratio fields on the third nested grid (grid 4) at 2100 UT on May 15, 1991. The clouds are depicted by white surfaces with $q_{c}=0.01 \mathrm{~g} \mathrm{~kg}^{-1}$, with the Sun illuminating the clouds from the west. The vapor mixing ratio in the planetary boundary layer is depicted by the shaded surface with $q_{v}=8 \mathrm{~g} \mathrm{~kg}^{-1}$. The flat surface is the ground. Areas formed by the intersection of clouds or the vapor field with lateral boundaries are flat surfaces, and visible ground implies $q_{v}<8 \mathrm{~g} \mathrm{~kg}^{-1}$. The vertical axis is height, and the back planes are the north and east sides of the grid domain. Reprinted from Pielke et al. [1997] with permission from Ecological Applications.

from satellite images that cumulus clouds form earliest over regions of large sensible heat flux and are suppressed over regions with large latent heat flux during relatively dry atmospheric conditions.

Clark and Arritt [1995], however, found while the cumulus cloud precipitation was delayed when the soil moisture was higher, the total accumulation of precipitation was greater. The largest rainfall was generally predicted to occur for moist, fully vegetated surfaces. De Ridder and Gallée [1998] found significant increases in convective rainfall in southern Israel associated with irrigation and intensification of agricultural practices, while De Ridder [1998] found that dense vegetation produces a positive feedback to precipitation. Baker et al. [2001] explored the influence of soil moisture and other effects on sea breeze-initiated precipitation in Florida.

Emori [1998] shows, using idealized simulations, how cumulus rainfall and soil moisture gradients interact so as to maintain a heterogeneous distribution of soil moisture. Taylor et al. [1997] concluded that such a feedback occurs in the Sahel of Africa, which acts to organize cumulus rainfall on scales of about $10 \mathrm{~km}$. Simpson et al. [1980,1993] have shown that cumulus clouds that merge together into a larger scale produce much more rainfall.

Chen and Avissar [1994b] used a model to show that land-surface moisture significantly affects the timing of onset of cumulus clouds and the intensity and distribu- 
tion of precipitation. Eltahir and Pal [1996] also explored the relation between surface conditions and subsequent cumulus convective rainfall. Mölders [1999] found that natural flooding and anthropogenic land-surface changes such as the drainage of marshes influence the water vapor supply to the atmosphere, clouds, and precipitation. Grasso [2000] has shown that dry line formation in the central Great Plains of the United States is critically dependent on the spatial pattern of soil moisture. Pan et al. [1996] concluded that increases in soil moisture enhanced local rainfall when the lower atmosphere was thermodynamically unstable and relatively dry but decreased rainfall when the atmosphere was humid and lacked sufficient thermal forcing to initiate deep cumulus convection.

These results illustrate that the effect of landscape evaporation and transpiration on deep cumulonimbus convection is quite nonlinear. These opposing effects further explain the apparent contradiction between the results reported by Lyons et al. [1996] and Pielke et al. [1997], as discussed earlier in this section. While increased moisture flux into the atmosphere can increase CAPE, the triggering of these deep cumulus clouds may be more difficult since the sensible heat flux may be reduced. The depth of the planetary boundary layer, for example, will be shallower if the sensible heat flux is less. Other studies which explore how vegetation variations organize cumulus convection include those by Anthes [1984], Vidale et al. [1997], Liu et al. [1999], Souza et al. [2000], and Weaver et al. [2000].

There are also studies of the regional importance of spatial and temporal variations in soil moisture and vegetation coverage [e.g., Fennessy and Shukla, 1999; Pielke et al., 1999a]. Using a model simulation covering Europe and the North Atlantic, for example, Schär et al. [1999] determined that the regional climate is very dependent on soil moisture content. They concluded that wet soils increase the efficiency of convective precipitation processes, including an increase in convective instability. Seth and Giorgi [1998] examined the role of model domain size with respect to the interpretation of the role of soil moisture in warm-season precipitation. Delworth and Manabe [1989] discuss how soil wetness influences the atmosphere by altering the partitioning of energy flux into sensible and latent heat components. They found that a soil moisture anomaly persists for seasonal and interannual timescales so that anomalous fluxes of sensible and latent heat also persist for long time periods. A similar conclusion was reported by Pielke et al. [1999a]. Wei and Fu [1998] found that the conversion of grassland into a desert in northern China would reduce precipitation as a result of the reduction in evaporation. Jones et al. [1998] discuss how surface heating rates over regional areas are dependent on surface soil wetness. Viterbo and Betts [1999] demonstrated significant improvement in large-scale numerical weather prediction when improved soil moisture analyses were used. Betts et al. [1996] reviewed these types of land-atmosphere in- teractions, as related to global modeling. Nicholson [2000] reviewed land-surface processes and the climate of the Sahel. Other recent regional-sale studies of the role of landscape processes in cumulus convection and other aspects of weather include those by Lyons et al. [1993], Carleton et al. [1994], Copeland et al. [1996], Huang et al. [1996], Bonan [1997], Sun et al. [1997], Bosilovich and Sun [1999], Liu and Avissar [1999a, 1999b], Adegoke [2000], and Li et al. [2000].

Segal et al. [1998] concluded that average rainfall in North America is increased as a result of irrigation, which is consistent with the influence of irrigation on CAPE as shown by Pielke and Zeng [1989] and the CAPE sensitivity analysis shown in Figure 9b. Pan et al. [1995] concluded that soil moisture significantly affects summer rainfall in both drought and flood years in the midwest of the United States. Kanae et al. [1994] concluded that deforestation in southeastern Asia since 1951 has resulted in decreases in rainfall in September in this region, when the large-scale monsoon flow weakens. Kiang and Eltahir [1999], Eastman et al. [2001], Lu et al. [2001], and Wang and Eltahir [1999, 2000a, 2000b] have used coupled regional atmospheric-vegetation dynamics models to demonstrate the importance of two-way interaction between the atmosphere and vegetation response. Hoffman and Jackson [2000], for example, propose that as a result of atmospheric-vegetation interactions in tropical savanna regions, anthropogenic impacts can exacerbate declines in precipitation. Shinoda and Gamo [2000] used observations to demonstrate a correlation between vegetation and convective boundary-layer temperature over the African Sahel. A clear conclusion from these studies is that both mesoscale and regional landscape patterning and average landscape conditions exert major controls on weather and climate.

\section{GLOBAL PERSPECTIVE}

The effect of well above average ocean temperatures in the eastern and central Pacific Ocean, which is referred to as "El Niño," has been shown to have a major effect on weather thousands of kilometers from this region [Shabbar et al., 1997]. The presence of the warm ocean surface conditions permits thunderstorms to occur there that would not happen with the average colder ocean surface. These thunderstorms export vast amounts of heat, moisture, and kinetic energy to the middle and higher latitudes, particularly in the winter hemisphere. This transfer alters the ridge and trough pattern associated with the polar jet stream [Hou, 1998]. This transfer of heat, moisture, and kinetic energy is referred to as "teleconnections" [Namias, 1978; Wallace and Gutzler, 1981; Glantz et al., 1991]. Almost two thirds of the global precipitation occurs associated with mesoscale cumulonimbus and stratiform cloud systems located equatorward of $30^{\circ}$ [Keenan et al., 1994]. In addition, much of the world's lightning occurs over tropical 


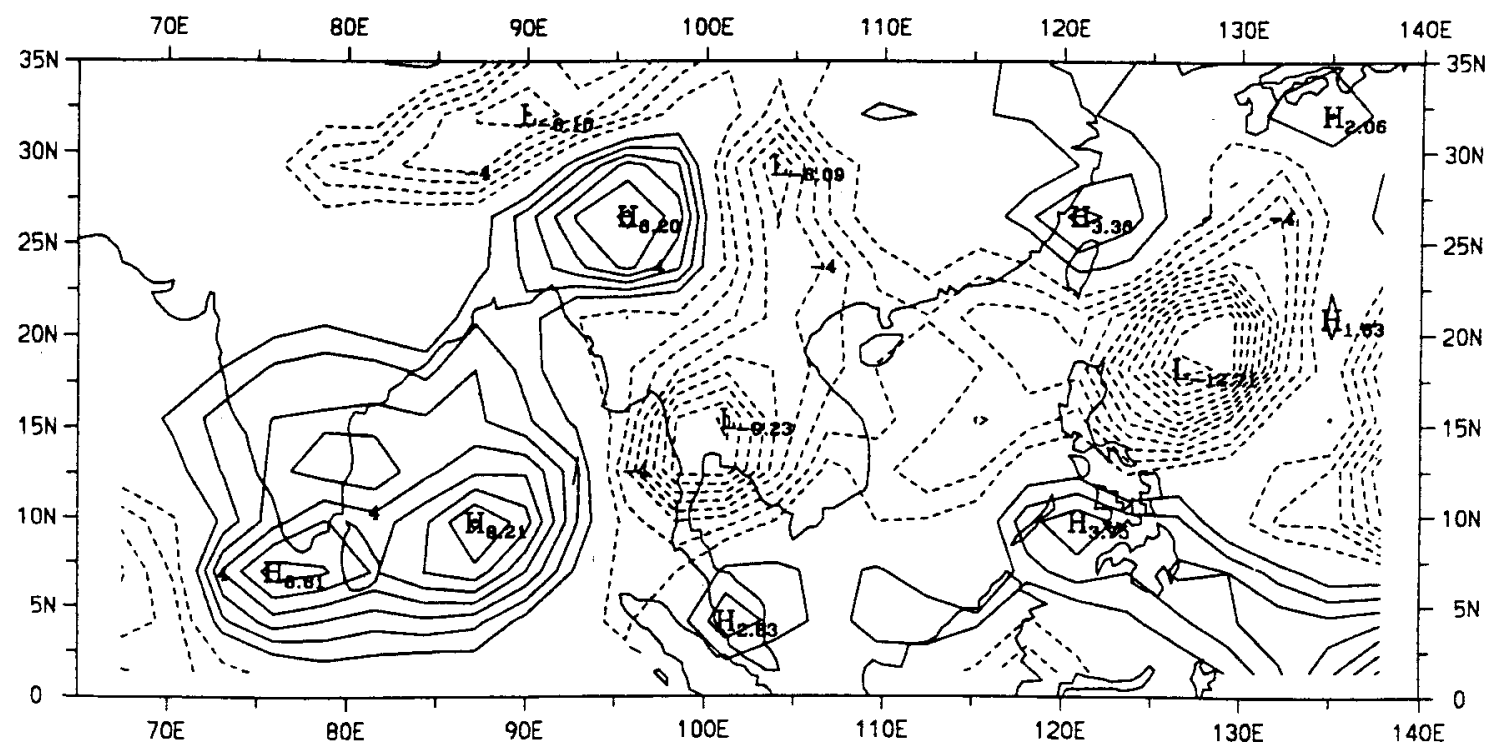

Figure 13. Illustration of how precipitation patterns in the tropics are altered in southeastern Asia and adjacent regions in a general circulation model (GCM) where two 10-year simulations were performed: one with the current global leaf area index (LAI) and one with the potential leaf area index, as estimated by Nemani et al. [1996]. From Chase et al. [1996].

landmasses, with maximums also over the midlatitude landmasses in the warm seasons [Lyons, 1999; Rosenfeld, 2000]. These tropical regions are also undergoing rapid landscape change [O'Brien, 2000].

As shown in the pioneering study by Riehl and Malkus [1958] and by Riehl and Simpson [1979], 1500-5000 thunderstorms (which they refer to as "hot towers") are the conduit to transport this heat, moisture, and wind energy to higher latitudes. Since thunderstorms occur only in a relatively small percentage of the area of the tropics, a change in their spatial patterns would be expected to have global consequences.

$W u$ and Newell [1998] concluded that sea surface temperature variations in the tropical eastern Pacific Ocean have three unique properties that allow this region to influence the atmosphere effectively: large magnitude, long persistence, and spatial coherence. Since land use change has the same three attributes, a similar teleconnection would be expected with respect to landscape patterns in the tropics. Dirmeyer and Shukla [1996], for example, found that doubling the size of deserts in a general circulation model (GCM) caused alterations in the polar jet stream pattern over northern Europe. Kleidon et al. [2000] ran a GCM with a "desert world" and a "green planet" in order to investigate the maximum effect of landscape change. However, these experiments, while useful, do not represent the actual effect of realistic anthropogenic land use change. Actual documented land use changes are reported, for example, by Baron et al. [1998], Giambelluca et al. [1999], Leemans [1999], and O'Brien [1997, 2000]. Giambelluca et al., for example, report albedo increases in the dry season of from 0.01 to 0.04 due to deforestation over northern Thailand.
Figure 13 illustrates how precipitation patterns in the tropics are altered in southeastern Asia and adjacent regions in a GCM where two 10-year simulations were performed: one with the current global seasonally varying leaf area index and one with the potential seasonally varying leaf area index, as estimated by Nemani et al. [1996]. No other landscape attributes were changed. Figure 13 presents the 10 -year average difference in precipitation for the month of July for the two GCM sensitivity experiments, which illustrates major pattern shifts in precipitation. As with El Niño, this alteration in tropical thunderstorm patterning teleconnects to higher latitudes, as shown in Figure 14b, where the 10-year averaged 500-mbar heights for July are presented. The 10-year averaged 500-mbar heights are also shown for January (Figure 14a).

The GCM produced a major, persistent change in the trough-ridge pattern of the polar jet stream, most pronounced in the winter hemisphere, which is a direct result of the land use change. Unlike an El Niño, however, where cool ocean temperatures return so that the El Niño effect can be clearly seen in the synoptic weather data, the landscape change is permanent. Figure 15 shows how the 10 -year averaged surface-air temperatures changed globally in this model experiment [Chase et al., 1996].

That landscape change in the tropics affects cumulus convection and long-term precipitation averages should not be a surprising result, based on the discussions earlier in this paper. For example, as reported by Pielke et al. [1999b], using identical observed meteorology for lateral boundary conditions, the Regional Atmospheric Modeling System (RAMS) was integrated for July-August 1973 for south Florida. Three experiments were 


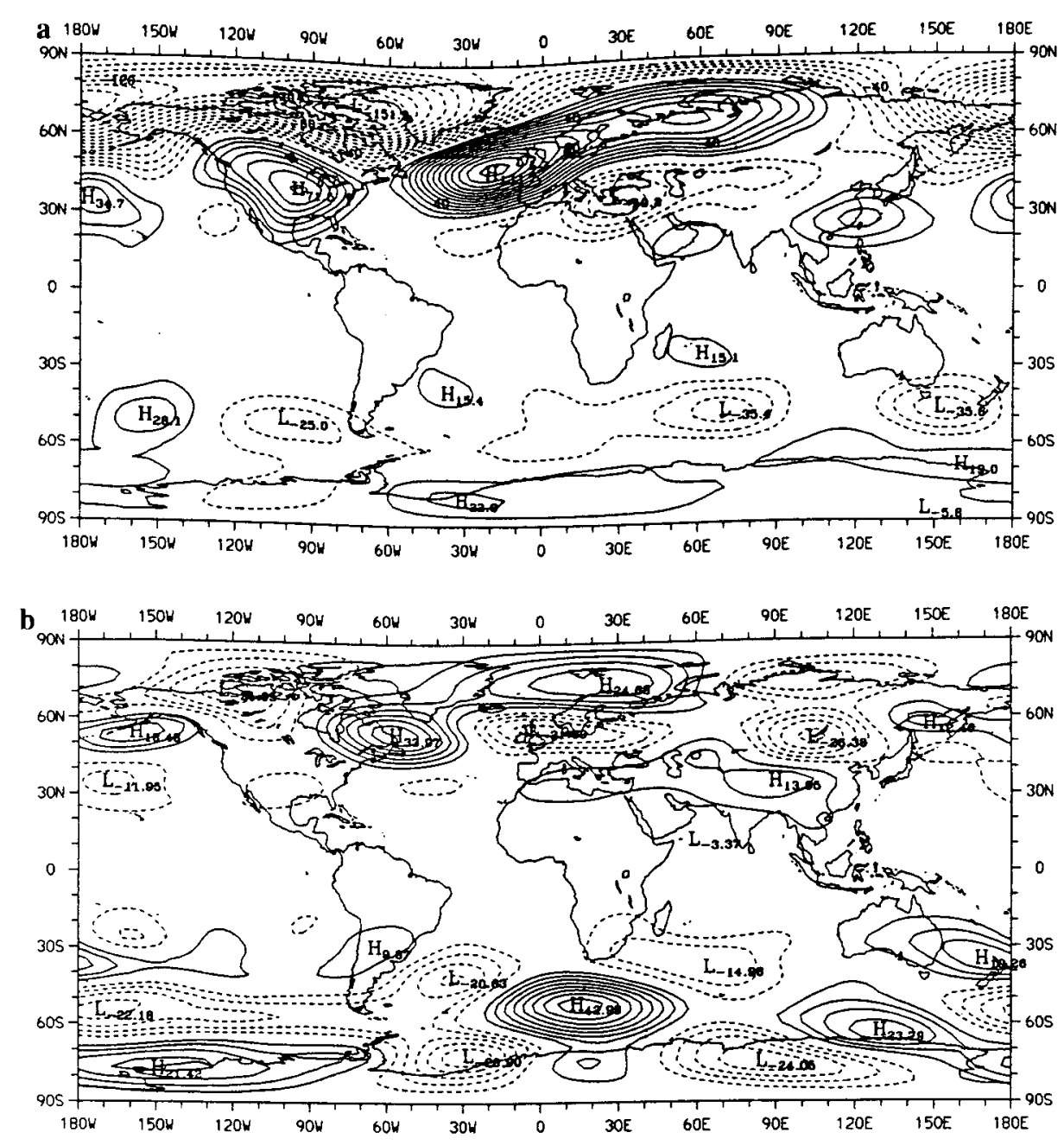

Figure 14. Ten-year averaged differences in 500-mbar height zonal wave numbers 1-6 only (actual LAI minus potential LAI). (a) January, contour 10 m. (b) July, contour 5 m. From Chase et al. [1996].

performed: one using the observed 1973 landscape, another using the 1993 landscape, and a third using the 1900 landscape, when the region was close to its natural state. Over the 2-month period, there was a $9 \%$ decrease in rainfall averaged over south Florida with the 1973 landscape and an 11\% decrease with the 1993 landscape, as compared with the model results when the 1900 landscape is used. The limited available observations of trends in summer rainfall over this region are consistent with these trends.

Chase et al. [2000] completed more general landscape change experiments using the Community Climate Model, Version 3 (CCM3) from the National Center for Atmospheric Research (NCAR). In this experiment, two 10-year simulations were performed using current landscape estimates and the potential natural landscape estimate under current climate. In addition to leaf area index (LAI) differences, albedo, fractional vegetation coverage, and aerodynamic roughness differences were included. While the amplitude of the effect of land use change on the atmospheric response was less than when the CCM2 GCM model was used, substantial alterations of the trough-ridge polar jet stream still resulted. Figures 16-18 shows the January 10-year averaged cumulus convective precipitation, 200-mbar height, and near-surface temperature differences between the two experiments. Despite the difference between the experiments with CCM 2 and CCM3, both experiments produce a wave number 3 change pattern in the polar jet stream. Pitman and Zhao [2000] and Zhao et al. [2001] have recently performed similar GCM experiments and have provided confirmation of the Chase et al. [1996, 2000] results.

Other studies support the result that there is a significant effect on the large-scale climate due to land-surface processes [e.g., Idso et al., 1975; Rodriguez-Iturbe et al., 1991a, 1991b; Entekhabi et al., 1992; Sud et al., 1993, 1995; Xue and Shukla, 1993, 1996; Dirmeyer, 1994; Foley et al., 1994, 1998; Milly and Dunne, 1994; Brubaker and Entekhabi, 1995; Claussen, 1995, 1998; Entekhabi and Brubaker, 1995; Eltahir, 1996; Xue, 1996, 1997; Xue et al., 1996; Betts et al., 1997; Broström et al., 1998; Ganopólsik et al., 1998; Ferranti and Molteni, 1999; Fraedrich et al., 1999; Pitman et al., 1999; Zeng and Neelin, 1999; Zeng et al., 1999; Burke et al., 2000; Costa and Foley, 2000; 


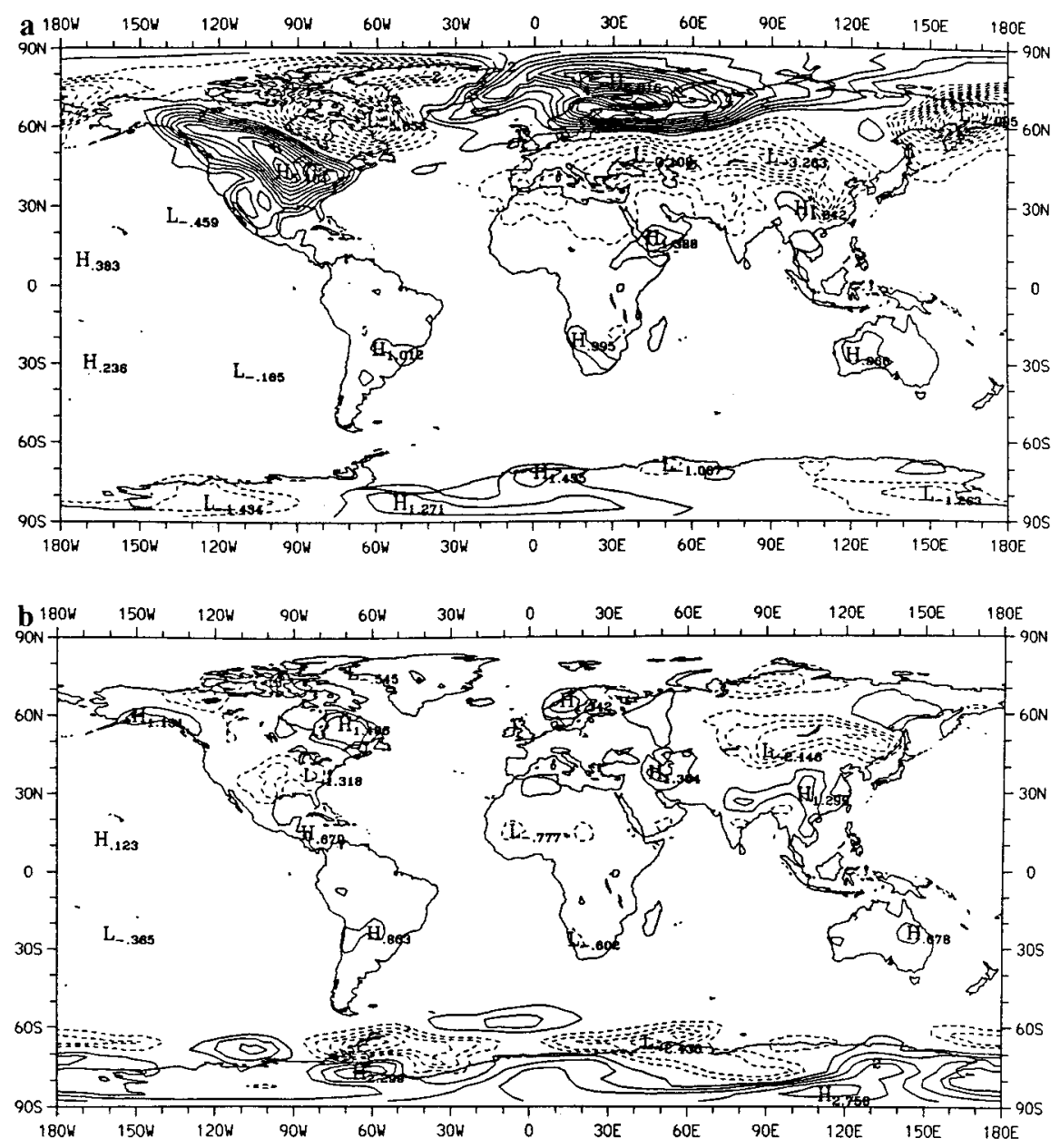

Figure 15. Ten-year averaged differences in $1.5-\mathrm{m}$ air temperature (actual LAI minus potential LAI) in kelvins for (a) January and (b) July. Contour interval is 0.5 K. From Chase et al. [1996].

Hoffmann and Jackson, 2000; Kleidon et al., 2000; Koster et al., 2000; Porporato et al., 2000; Ramírez and Senareth, 2000; Texier et al., 2000]. Zeng et al. [1998] found, for example, that the root distribution influences the latent heat flux over tropical land. Kleidon and Heimann [2000] determined that deep-rooted vegetation must be adequately represented in order to realistically represent the tropical climate system. Dirmeyer and Zeng [1999] concluded that evaporation from the soil surface accounts for a majority of water vapor fluxes from the surface for all but the most heavily forested areas, where transpiration dominates. Recycled water vapor from evaporation and transpiration is a major component of the continental precipitation. Brubaker et al. [1993] found that locally contributed water vapor to precipitation generally lies between 10 and $30 \%$ but can be as high as $40 \%$. Eltahir and Bras [1994] concluded that there is $25-35 \%$ recycling of precipitation water in the Amazon. Trenberth [1999] provides a review of atmospheric moisture recycling. Dirmeyer [1999] concluded that interannual variations of soil wetness are large enough to influence climate GCM simulations.

An important conclusion from such studies is that land use change directly alters local and regional heat and moisture fluxes in two ways. First, the local and regional CAPE is changed since the Bowen ratio is changed as the surface heat and moisture budgets are altered. Second, larger-scale heat and moisture convergence and associated large-scale wind circulations can be changed as a result of changes in the large-scale atmospheric pressure field due to the landscape change.

As a general conclusion, these regional and global model studies indicate that the spatial patterning of deep cumulus convection particularly in the tropics and midlatitude summers is significantly altered as a result of landscape changes. These alterations in cumulus convection teleconnect to middle and higher latitudes, which alters the weather in those regions. This effect appears to be most clearly defined in the winter hemisphere.

\section{CONCLUSIONS}

This paper demonstrates that vegetation and soil processes and change directly affect the surface energy and moisture fluxes into the atmosphere. This alteration in 


\section{CONVECTIVE PRECIPITATION DIFFERENCE}

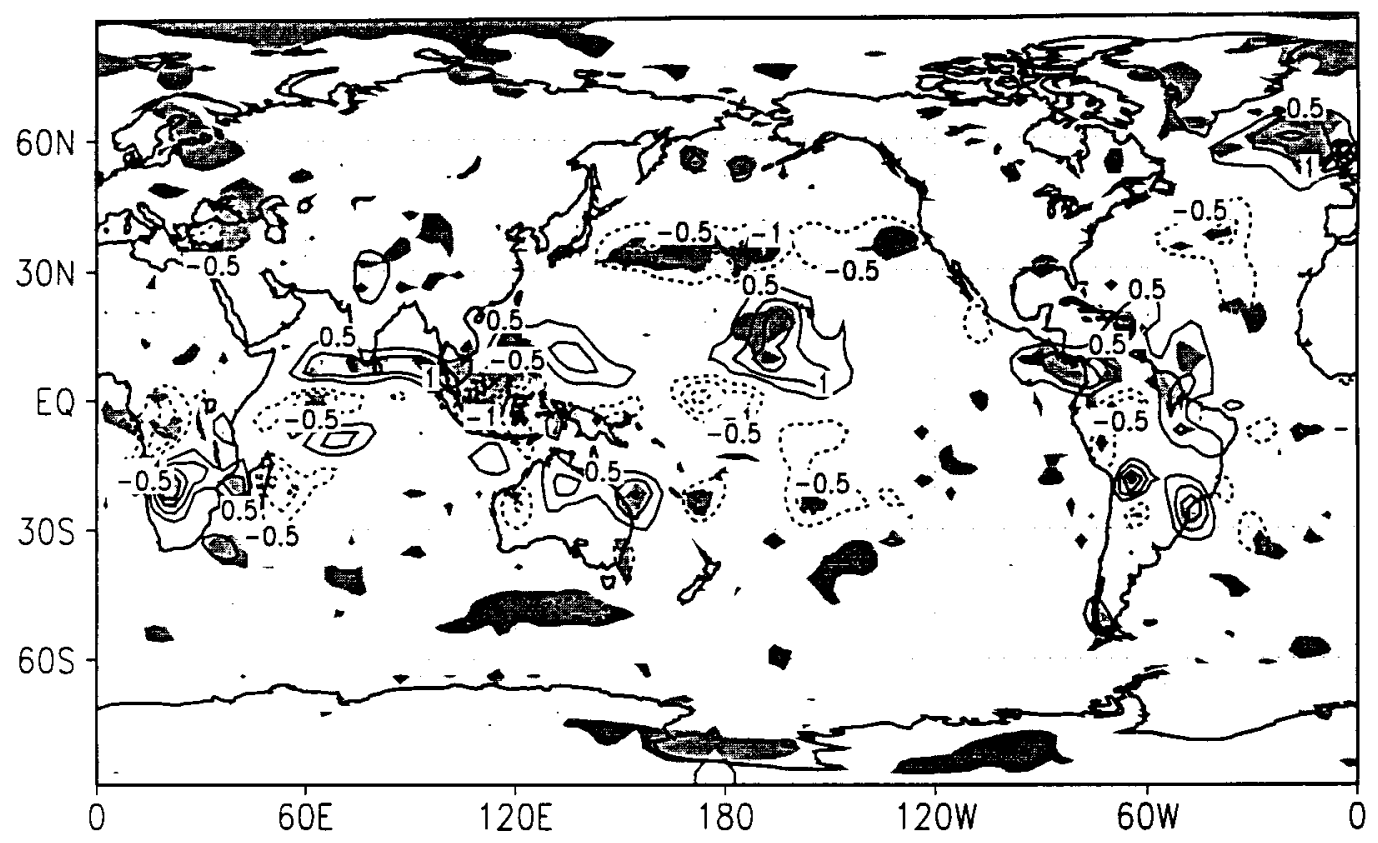

Figure 16. Convective precipitation differences (current minus natural, contour by $0.5 \mathrm{~mm} \mathrm{~d}^{-1}$ ) using a nine-point spatial filter for easier visibility. Lighter shading represents the $90 \%$ significance level for a one-sided $t$-test. Darker shading represents the 95\% significance level. Reprinted from Chase et al. [2000] with permission from Springer-Verlag.

\section{$200 \mathrm{mb}$ HEIGHT DIFFERENCE}

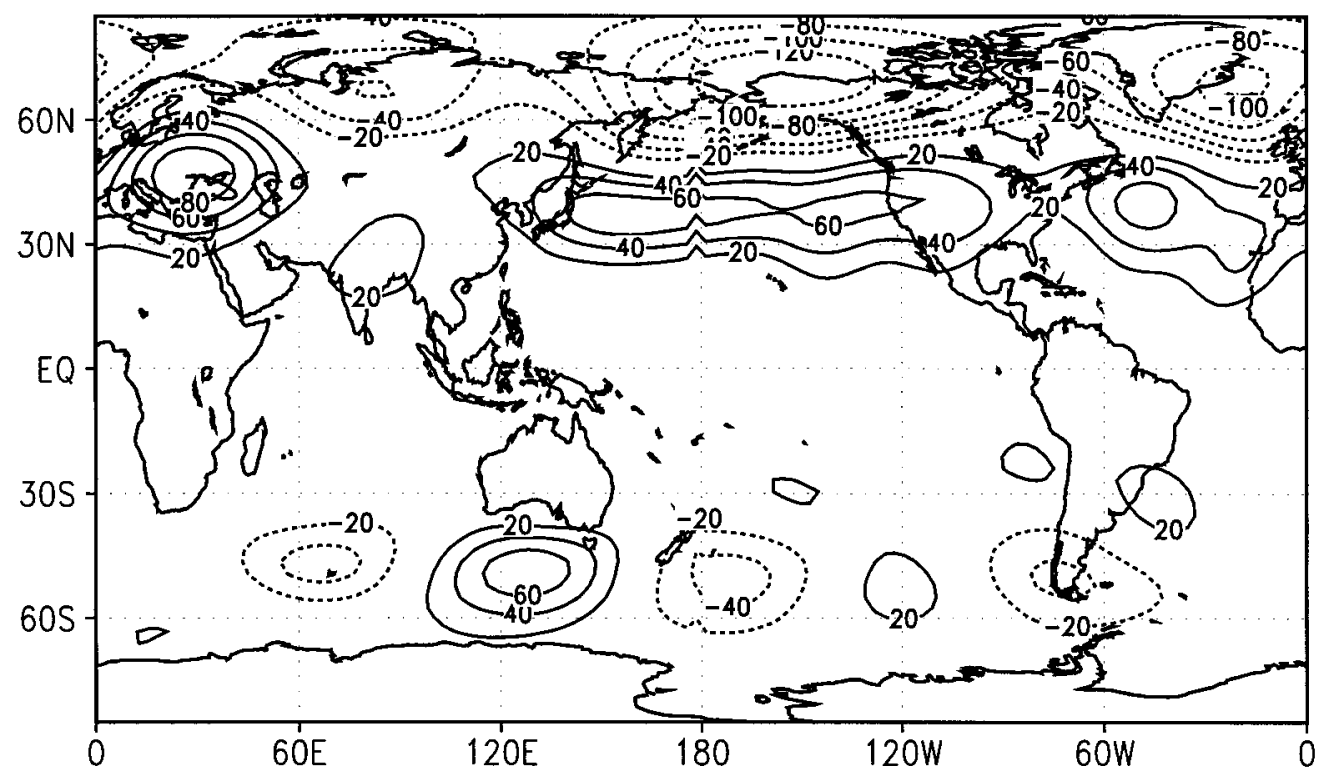

Figure 17. The 200-hPa height difference (current minus natural landscapes). Contour interval is $20 \mathrm{~m}$. Reprinted from Chase et al. [2000] with permission from Springer-Verlag. 


\section{NEAR SURFACE TEMPERATURE DIFFERENCE}

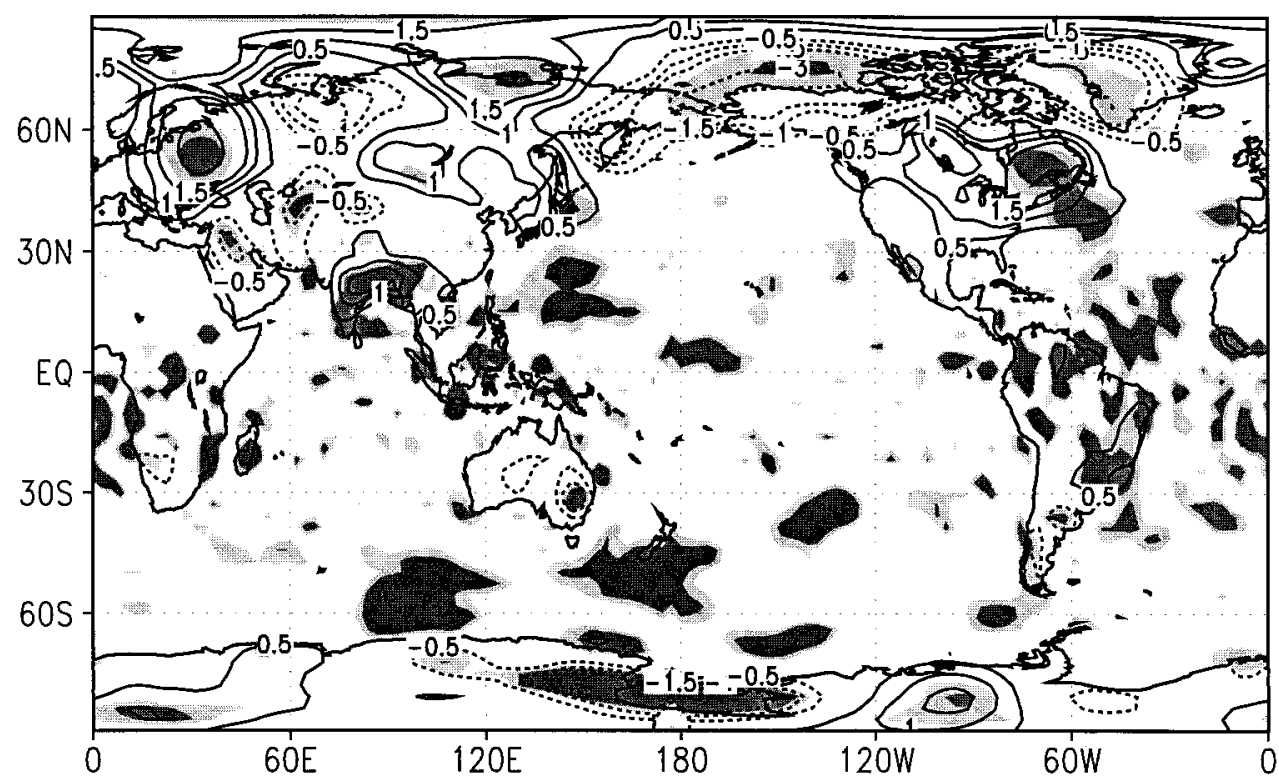

Figure 18. Difference in near-surface air temperature (current minus natural landscapes) using a nine-point spatial filter for easier visibility. Contour intervals are $0.5^{\circ}, 1.0^{\circ}, 1.5^{\circ}$, and $3.0^{\circ} \mathrm{C}$. Lighter shading represents the $90 \%$ significance level for a one-sided $t$-test. Darker shading represents the $95 \%$ significance level. Reprinted from Chase et al. [2000] with permission from Springer-Verlag.

fluxes directly modifies the environment for thunderstorms. Since thunderstorms are an effective conduit for heat, moisture, and momentum to higher latitudes, landscape processes exert a major influence on global weather and climate. In the context of climate, soil and vegetation dynamics are as much a part of the climate system as are atmospheric variables [Hayden, 1998; Pielke, 1998; Wang and Eltahir, 2000a, 2000b]. New observational platforms, such as the Tropical Rainfall Measuring Mission [Tao et al., 2001], offer opportunities to develop improved understanding of the role of surface-atmosphere interactions on cumulus convective rainfall.

\section{APPENDIX A: BASIC CONCEPTS}

\section{A1. Dry Adiabatic Lapse Rate}

An equation for potential temperature $\theta$ can be written as

$$
\frac{\partial \theta}{\partial t}+\vec{V} \cdot \nabla \theta=\frac{d \theta}{d t}=Q .
$$

If no heat $Q$ is added to or removed from a parcel, the potential temperature must be constant [e.g., Pielke, 1984, chapter 2]. Therefore, for this situation,

$$
\frac{d \theta}{d z}=0
$$

is a statement that there are no heat changes for a vertically displaced parcel. From the definition of $\theta[\theta=$ $\left.T_{v}(1000 \mathrm{mbar} / p)^{R_{d} / C_{p}}\right]$ therefore, after differentiating logarithmically with height,

$$
\frac{1}{\theta} \frac{d \theta}{d z}=0=\frac{1}{T_{v}} \frac{d T_{v}}{d z}-\frac{R_{d}}{C_{p} p} \frac{d p}{d z}
$$

is an equivalent statement of (A2). $T_{v}=T_{\text {dry }}(1+$ $0.61 w$ ), where $w$ is the mixing ratio. See Pielke [1984, p. 8] for a derivation of virtual temperature. $T_{\text {dry }}$ is the thermometer temperature. Assuming hydrostatic balance (i.e., $d p / d z=-\rho g$ ), equation (A3), after rearranging, becomes

$$
\frac{d T_{v}}{d z}=\frac{-R_{d} T \rho}{p} \frac{g}{C_{p}}=-\frac{g}{C_{p}}=-\gamma_{d},
$$

where the ideal gas law $\left(p=\rho R_{d} T_{v}\right)$ has been applied. For the Earth's troposphere, $g / C_{p} \cong 1^{\circ} \mathrm{C} 100 \mathrm{~m}^{-1}$. The variable $\gamma_{d}$ is referred to as the dry adiabatic lapse rate.

On a thermodynamic diagram, lines of constant $\theta$ correspond to a temperature lapse rate equal to $-1^{\circ} \mathrm{C}$ $100 \mathrm{~m}^{-1}$. To simplify the notation, $T$ is used hereinafter for $T_{v}$.

\section{A2. Wet Adiabatic Lapse Rate}

When a parcel is lifted, temperature decreases, as is evident from (A4). Since air cannot hold as much water vapor at colder temperatures [e.g., see Wallace and 
Hobbs, 1977, p. 73], sufficient lifting will result in condensation (deposition) when the vapor pressure of the water vapor, $e$, becomes equal to the saturation vapor pressure $e_{s}$, with respect to water (or ice). Since $e / e_{s}=$ 1 corresponds to $w / w_{s}=1$, where $w$ is the mixing ratio (grams of water vapor per grams of air; i.e., $\rho_{v} / \rho$, where $\rho_{v}$ is the density of water vapor and $\rho$ is the density of the air), the height where $w=w_{s}$ first occurs is referred to as the lifting condensation level (LCL).

The value of $w$ for the parcel is determined by measuring the dew point temperature. The dew point temperature is defined as the temperature at which condensation first happens as a result of cooling at constant pressure. An analogous temperature (the frost point) is defined for the first occurrence of deposition due to cooling at constant pressure.

The temperature of the parcel determines the maximum amount of water vapor (i.e., the saturation mixing ratio $w_{s}$ ) that can be contained without condensation or deposition. This relation between saturation mixing ratio and temperature is given for realistic tropospheric conditions as [from Pielke, 1984, p. 234].

Liquid water

$$
w_{s} \cong \frac{3.8}{\bar{p}} \exp \left[\frac{21.9(\bar{T}-273.2)}{\bar{T}-7.7}\right]
$$

Ice

$$
w_{s_{i}} \cong \frac{3.8}{\bar{p}} \exp \left[\frac{17.3(\bar{T}-273.2)}{\bar{T}-35.9}\right]
$$

Lines of constant saturation mixing ratio from a formulation such as (A5) are usually drawn on thermodynamic diagrams as dashed or dotted lines.

Since water vapor content up to the LCL is constant, $w$ is a constant as a parcel ascends or descends below the LCL. It is important to recognize, however, that a constant value of $w$ does not indicate that the dew point temperature is constant with height. As the parcel ascends, expansion results in a reduction in the vapor pressure $e$ with height, as seen from the ideal gas law (i.e., $e=\rho_{v} R_{v} T$, where $\rho_{v}$ is the density and $R_{v}$ is the gas constant of the water vapor). Expansion requires that $\rho_{v}$ become less, and (A4) indicates that temperature decreases with height as well. Thus the temperature to which a parcel must be cooled isobarically in order to achieve condensation (sublimation) becomes lower at higher heights (i.e., lower pressures) since $e$ decreases with height. Therefore, while $w=\rho_{v} / \rho$ is constant with height below the LCL, $d T_{D} / d z$ is less than zero.

The phase change of water at and above the LCL permits a source of a heat. Equation (A3) can be generalized to represent this source term as

$$
\frac{1}{\theta} \frac{d \theta}{d z}=\frac{1}{T} \frac{d T}{d z}-\frac{R_{d}}{C_{p} p} \frac{d p}{d z}=-\frac{L}{C_{p} T} \frac{d w_{s}}{d z},
$$

where $d w_{s} / d z$ is the change of saturation mixing ratio with height, which, when negative, represents the amount of water vapor converted to another phase. The latent heat of phase change is given by $L$.

Rearranging (A7) and substituting the hydrostatic relation yields

$$
\frac{d T}{d z}=-\frac{L}{C_{p}} \frac{d w_{s}}{d z}-\frac{R_{d} T \rho g}{p C_{p}}=-\frac{L}{C_{p}} \frac{d w_{s}}{d z}-\frac{g}{C_{p}},
$$

where the gas law has been applied to simplify the last term on the right. By the chain rule of calculus, $d w_{s} / d z$ can be written as

$$
\frac{d w_{s}}{d z}=\frac{d w_{s}}{d T} \frac{d T}{d z} .
$$

Substituting (A9) into (A8) and rearranging yields

$$
\frac{d T}{d z}=-\frac{g}{C_{p}} /\left[1+\frac{L}{C_{p}} \frac{d w_{s}}{d T}\right]=\frac{-\gamma_{d}}{\left[1+\frac{L}{C_{p}} \frac{d w_{s}}{d T}\right]}=-\gamma_{m}
$$

where $\gamma_{m}$ is referred to as the moist adiabatic lapse rate. When the phase change is from water vapor to liquid water, $L$ corresponds to the latent heat of condensation $\left(L \cong 2.5 \times 10^{6} \mathrm{~J} \mathrm{~kg}^{-1}\right), w_{s}$ is the saturation mixing ratio with respect to liquid water (e.g., equation (A5)), and $\gamma_{m}$ is often called a water adiabat or a wet adiabat. When the phase change is to ice, $L$ is the latent heat of deposition $\left(L \cong 2.88 \times 10^{6} \mathrm{~J} \mathrm{~kg}^{-1}\right)$ and $w_{s}$ is the saturation mixing ratio with respect to ice (e.g., equation (A6)). On most thermodynamic diagrams, except those specifically designed for the upper troposphere, where, for instance, the prime forecast consideration is the analysis for jet contrails, water adiabats are the ones most frequently plotted.

From (A10), irrespective of which moist adiabat is used, since $d w_{s} / d T$ is positive,

$$
\gamma_{m} \leq \gamma_{d}
$$

in all circumstances. Also, since $d w_{s} / d T$ becomes small for colder temperatures, $\gamma_{m} \cong \gamma_{d}$ in cold air. Lines of $\gamma_{m}$ are often indicated on thermodynamic diagrams as dashed lines in the same color as the solid lines of $\gamma_{d}$.

There are two interpretations of moist ascent along a $\gamma_{m}$ lapse rate. If the liquid water or ice is carried along with the parcel, then during subsequent descent this water can convert back to water vapor (i.e., evaporation for liquid water, sublimation for ice). For this situation the phase change process is completely reversible, and the lines of $\gamma_{m}$ are referred to as saturated adiabats. On the other hand, if the liquid water or ice is interpreted to precipitate out of the parcel, a subsequent descent of the parcel will not permit the attainment of the original water vapor content. With this interpretation, the lines of $\gamma_{m}$ are referred to as pseudoadiabats and the process of lifting above the LCL is considered irreversible. 
Two additional quantities are used to describe the moist thermodynamic stratification of the atmosphere: the equivalent potential temperature and the wet bulb potential temperature. To illustrate these two quantities, they will be derived in their approximate forms. Iribarne and Godson [1974] and Bohren and Albrecht [1998] provide more precise derivations. Equation (A7) can be written in the form

$$
\frac{1}{\theta} \frac{d \theta}{d z}=-\frac{L}{C_{p} T} \frac{d w_{s}}{d z} \cong-\frac{L}{C_{p}} \frac{d}{d z}\left(\frac{w_{s}}{T}\right)
$$

as long as the approximation $T^{-1}\left|d w_{s} / d z\right| \gg w_{s} T^{-2} \mid d T /$ $d z \mid$ is valid (which it is for reasonable atmospheric conditions within the troposphere). Since at low temperatures the saturation mixing ratio goes to zero more rapidly than temperature, $w_{s} / T$ approaches zero at absolute zero. Therefore, treating $L$ and $C_{p}$ as constants, (A12) can be integrated from an observed temperature to absolute zero yielding the approximate formula (a more exact form of $\theta_{e s}$ can be obtained from $T_{e s}=T_{v}+$ $\left(L / C_{p}\right) w_{s}$, where $T_{e}$ is the isobaric equivalent temperature and thus $\theta_{e s}=T_{e s}(1000 / p)^{R d / c p}$ can be used to compute $\left.\theta_{e s}\right)$ :

$$
\theta_{e s}=\theta \exp \left(\frac{L w_{s}}{C_{p} T}\right)
$$

When the air is not saturated, the equivalent potential temperature can be written as

$$
\theta_{e}=\theta \exp \left(\frac{L w}{C_{p} T}\right)
$$

The equivalent potential temperature therefore represents the potential temperature that would occur if all of the water was condensed (when $L$ corresponds to the latent heat of condensation) and the resultant heat is used to warm the parcel to a higher potential temperature.

The wet bulb potential temperature is also derived from (A12). Equation (A12) can be rewritten in its approximate form as

$$
\frac{d(\ln \theta)}{d z}=-\frac{L}{C_{p}} \frac{d}{d z}\left[\frac{w_{s}}{T}\right] .
$$

Equation (A15) can be integrated between the current values of $\theta$ and $w_{s}$ and the values of potential temperature $\theta_{W}$ and saturation mixing ratio $w_{s}^{\prime}$ it would have if water vapor were added to the air parcel so as to cause saturation. This yields

$$
\int_{\theta}^{\theta_{W}} \frac{d}{d z} \ln \theta d z=-\frac{L}{C_{p}} \int_{w_{s}}^{w_{s}^{\prime}} \frac{d}{d z}\left[\frac{w_{s}}{T}\right] d z
$$

or

$$
\ln \frac{\theta_{W}}{\theta}=-\frac{L}{C_{p}}\left[\frac{w_{s}}{T}-\frac{w_{s}^{\prime}}{T_{W}}\right]
$$

$$
\theta_{W}=\theta \exp \left[-\frac{L}{C_{p}}\left(\frac{w_{s}}{T}-\frac{w_{s}^{\prime}}{T_{W}}\right)\right] .
$$

The value of the wet bulb temperature in (A18) can be obtained for an isobaric process from the first law of thermodynamics in the form

$$
C_{p} d T=-L d w_{s}
$$

which, after integrating over the same type of limits as applied to obtain (18), yields

$$
C_{p}\left(T-T_{W}\right)=-L\left[w_{s}-w_{s}^{\prime}\right]
$$

or

$$
T_{W}=T-\frac{L}{C_{p}}\left(w_{s}^{\prime}-w_{s}\right) .
$$

Since moistening an air parcel elevates the dew point temperature, while the evaporation of water cools the temperature, $T_{D} \leq T_{W} \leq T$.

Equal values of $\theta_{e}$ and $\theta_{W}$ correspond to lines of constant moist adiabatic lapse rate, $\gamma_{m}$. Both $\theta_{e}$ and $\theta_{W}$ are derived so as to account for the decrease in temperature with height of a saturated air parcel, as latent heat is continually released.

\section{A3. Lifting Condensation Level}

An air parcel ascends dry adiabatically $(d \theta / d z=0)$ until saturation is attained. The moisture content of a parcel is specified by the mixing ratio. The height at which the ascending parcel first becomes saturated is called the lifting condensation level (LCL). Below the LCL, $\theta, \theta_{e}$, and $\theta_{W}$ remain constant in the absence of entrainment of air with different thermodynamic properties. Entrainment is the term used to describe the mixing of adjacent air parcels of different thermodynamic characteristics. All three forms of potential temperature therefore are conserved with respect to dry air motions. Above the LCL, however, only $\theta_{e}$ and $\theta_{W}$ of a parcel remain constant in the absence of entrainment. Therefore only $\theta_{e}$ and $\theta_{W}$, and not $\theta$, are conserved with respect to saturated air motions.

\section{A4. Concept of Static Stability}

Since force is equal to a mass times an acceleration (i.e., Newton's second law), the vertical equation of motion in the atmosphere can be written as

$$
\frac{d^{2} z}{d t^{2}}=\frac{d w}{d t}=-\frac{1}{\rho} \frac{\partial p}{\partial z}-g,
$$

where in (A22) $w$ is vertical motion. The two forces on the right side of (A22) are the vertical pressure gradient force and the gravitational acceleration. When these two forces are equal and opposite, the atmosphere is said to be in hydrostatic balance. Correspondingly, an imbalance of the two forces results in an acceleration.

In terms of an air parcel, it is convenient to write the hydrostatic version of (A22) for the ambient (i.e., sur- 
rounding) atmosphere (denoted by a subscript $e$ ) and the complete form of (A22) (denoted by a subscript $p$ ) for the parcel.

The vertical equations of motion of the parcel and of the surrounding atmosphere are

$$
\begin{gathered}
\left|\frac{\partial p}{\partial z}\right|_{e}=-\rho_{e} g \\
\frac{d w}{d t}=-\left.\frac{1}{\rho_{p}} \frac{\partial p}{\partial z}\right|_{p}-g .
\end{gathered}
$$

In applying (A23) and (A24), it is assumed that the vertical pressure gradient acting on the parcel is identical to the vertical pressure gradient of the atmosphere at the same level, i.e.,

$$
\left.\frac{\partial p}{\partial z}\right|_{e}=\left.\frac{\partial p}{\partial z}\right|_{p}=\frac{\partial p}{\partial z} .
$$

Expression (A24) can then be written, after rearranging, as

$$
\frac{d w}{d t}=g\left[\frac{\rho_{e}-\rho_{p}}{\rho_{p}}\right] .
$$

Thus a parcel starting at rest will accelerate upward if it is less dense than the surrounding air. If $\rho_{e}=\rho_{p}$, a parcel at rest will stay at rest, while a parcel in motion will continue to move at a constant speed.

Using the ideal gas law for the parcel and for the ambient atmosphere,

$$
\rho_{e}=p / R_{d} T_{e} \quad \rho_{p}=p / R_{d} T_{p},
$$

(A26) can be rewritten as

$$
\frac{d w}{d t}=g \frac{T_{p}-T_{e}}{T_{e}} .
$$

Therefore a parcel starting at rest will accelerate upward if it is warmer than the surrounding air.

Using a Taylor series expansion, the response of a parcel to forced motion from its height of origin in the atmosphere can be evaluated:

$$
\begin{gathered}
T_{e}=T_{o}+\left.\frac{d T}{d z}\right|_{e} \delta z+\left.\frac{1}{2} \frac{d^{2} T}{d z^{2}}\right|_{e}(\delta z)^{2}+\cdots \\
T_{p}=T_{o}+\left.\frac{d T}{d z}\right|_{p} \delta z+\left.\frac{1}{2} \frac{d^{2} T}{d z^{2}}\right|_{p}(\delta z)^{2}+\cdots,
\end{gathered}
$$

where $T_{o}$ is the temperature at the level at which the parcel originated.

If $\delta z$ is small,

$$
T_{e} \cong T_{o}-\gamma \delta z \quad T_{p} \cong T_{o}-\gamma_{d} \delta z,
$$

where $\gamma=-d T /\left.d z\right|_{e}$ is the lapse rate of the environment and $\gamma_{d}$ is the lapse rate of a parcel undergoing dry adiabatic motion (i.e., $\gamma_{d}=g / c_{p}=-\left.(d T / d z)\right|_{p}$; see equation (A4)). Equation (A28) can therefore be approximated by

$$
\frac{d w}{d t} \cong g \frac{\left(\gamma-\gamma_{d}\right)}{T_{e}} \delta z .
$$

In terms of (A32), the following definitions are used when referring to a dry atmosphere: an unstable equilibrium exists when $\gamma>\gamma_{d}$; a neutral equilibrium exists when $\gamma=\gamma_{d}$; and a stable equilibrium exists when $\gamma<$ $\gamma_{d}$. In the atmosphere, $\gamma<\gamma_{d}$ at almost all locations except near the ground on sunny days, over water when colder air advects over it, and at the top of clouds, particularly at sunset.

Since values of constant potential temperature $\theta$ are equivalent to $\gamma_{d}$,

$$
\gamma>\gamma_{d}, \quad \gamma=\gamma_{d}, \quad \gamma<\gamma_{d}
$$

are equivalent to

$$
\frac{\partial \theta}{\partial z}<0, \quad \frac{\partial \theta}{\partial z}=0, \quad \frac{\partial \theta}{\partial z}>0,
$$

respectively. Partial derivatives are used here to emphasize that the potential temperature lapse rate is referred to rather than the value of $\theta$ following a parcel. When $\partial \theta / \partial z<0$, the lapse rate $\gamma$ is said to be superadiabatic.

Corresponding definitions can be made for a saturated environment, except $\gamma_{d}$ is replaced by $\gamma_{m}$. If the air is saturated, $\gamma>\gamma_{m}$ is unstable and cumuliform clouds result, $\gamma=\gamma_{m}$ is neutral and cumuliform clouds result, and $\gamma<\gamma_{m}$ is stable and stratiform clouds result.

Since values of constant equivalent and wet bulb potential are equivalent to constant values of $\gamma_{m}$, a general terminology relating lapse rates and the different $\theta$ forms of potential temperature can be derived.

Up to this point, thermodynamic stability has referred to parcel motion. Often, however, entire layers of the atmosphere are lifted as a result of large-scale ascent. This lifting can result in significant changes in the atmospheric lapse rates, $\gamma$. When $\partial \theta_{e} / \partial z>0$, the layer becomes more stable with lifting, while when $\partial \theta_{e} / \partial z<$ 0 , the stratification becomes less stable. When $\partial \theta_{e} / \partial z$ becomes more negative, the atmosphere becomes more conducive to cumuliform convection. When $\partial \theta_{e} / \partial z<0$, the layer is variously referred to as (1) convectively unstable, since cumulus convection results when saturation is realized in such an atmosphere; (2) potential instability, since organized lifting must occur before saturation is actually realized; or (3) layer instability, since it is the lifting of a layer of the atmosphere that increases the instability and permits saturation to occur.

As a qualitative guide, dry air above moist air is a fingerprint of a convectively unstable atmosphere and is one criteria looked for in predicting severe thunderstorm outbreaks. In using these thermodynamic definitions, it is important to remember that conditional instability refers to a parcel, while convective instability refers to a layer. 


\section{A5. Convective Parameters}

Using these basic concepts in weather analyses, there are several derived thermodynamically related parameters that are valuable in estimating if and when convection will occur and how intense it will be. These are as follows:

A5.1. Equilibrium level (EL). This is the height in the atmosphere at which the temperature of an air parcel, $T_{p}$, equals the temperature of the environment at that level, $T_{e}$. Below this height for some distance, $T_{p}>$ $T_{e}$. This height closely corresponds to the average heights of cumulus cloud tops. Cumulus clouds which exceed this height are referred to as overshooting tops since they exceed their equilibrium level.

A5.2. Convective temperature $\left(T_{c}\right)$. This is a temperature near the surface corresponding to a dry adiabatic environmental lapse rate (created as a result of surface heating by insolation and resultant mixing) which is high enough so that parcel ascent from the shallow superadiabatic layer near the surface reaches a height at which condensation occurs. It often closely corresponds to the maximum daytime surface temperature.

A5.3. Convective condensation level $(\mathrm{CCL})$. This is the height of condensation associated with $T_{c}$. Condensation at this height is manifested initially by shallow cumulus clouds which represent the tops of buoyant turbulent eddies within the boundary layer. Once the $\mathrm{CCL}$ is attained, surface temperatures generally do not exceed $T_{c}$ as a result of the shading of the ground by the clouds and the increased winds near the surface as the cumulus clouds themselves begin to enhance mixing within the layers below the CCL. The CCL is always higher than or equal to the LCL. The most accurate way to compute the CCL is to compute the average $w$ within a height $z_{i}$ from the surface. The depth $z_{i}$ corresponds to the height of the layer with a near-adiabatic lapse rate. When $z_{i}$ reaches a height such that the value of the average $w$ over the depth $z_{i}$ attains its saturated value at $z_{i}$, then $z_{i}$ corresponds to the CCL.

A5.4. Level of free convection (LFC). This is the height at which a parcel mechanically lifted from near the surface will initially attain a temperature warmer than the ambient air. The parcel will subsequently rise from its own buoyancy.

A5.5. Convective available potential energy (CAPE). This energy is proportional to the temperature excess of a parcel between the LFC and the EL. This temperature excess can be described in terms of the vertical profile of $\theta$ and $\theta_{e}$. The mechanical energy required to lift a parcel to the LFC is termed a negative buoyant energy. CAPE is also called positive buoyant energy.

A5.6. Convective inhibition (CIN). This is the heat energy that must be added to the lower levels of the profile in order to make the potential temperature at the LFC equal to the potential temperature near the surface (i.e., $\partial \theta / \partial z=0$ ). This energy removes the negative buoyant energy.

A5.7. Lifted index (LI). This measure of stability is defined as

$$
\mathrm{LI}=T_{500 \mathrm{mbar}}-T_{p 500 \mathrm{mbar}},
$$

where $T_{p 500 \mathrm{mbar}}$ is the temperature of a parcel lifted at a constant $\theta$ to the LCL and at a constant $\theta_{e}$ to $500 \mathrm{mbar}$. $T_{500 \mathrm{mbar}}$ is the observed temperature at 500 mbar. Values of LI $>0$ are generally associated with no significant cumulus convection; $0>\mathrm{LI}>-4$ are associated with showers; $-4>$ LI $>-6$ are associated with thunderstorms; and LI $<-6$ are associated with severe thunderstorms.

A5.8. Precipitable water (P). This parameter is the vertical integral of water depth if all water vapor in a column were condensed out, defined in terms of $\mathrm{g}$ $\mathrm{cm}^{-2} \equiv 1 \mathrm{~cm}$ of water depth as

$$
P=\int_{\text {surface }}^{\infty} \rho_{v} d z=\int_{\text {surface }}^{\infty} w \rho d z
$$

\section{A6. Local Wind Circulations}

As shown by Pielke and Segal [1986], the hydrostatic pressure gradient equation can be written for shallow atmospheric systems as

$$
\frac{\partial p^{\prime}}{\partial z}=\frac{\theta^{\prime}}{\alpha_{0} \theta_{0}} g,
$$

where $\alpha_{0}=1 / \rho_{0}$ and $\rho_{0}$ is the mean density of air through the depth in which the hydrostatic equation is evaluated. Differentiating (A33) with respect to $x$ and $y$ (i.e., $\nabla_{H}$ ), reversing the order of differential operations, and assuming $\alpha_{0}$ and $\theta_{0}$ are constants yields

$$
\frac{\partial}{\partial z}\left(\nabla_{2 \mathrm{D}} p^{\prime}\right)=\frac{g}{\alpha_{0} \theta_{0}} \nabla_{2 \mathrm{D}} \theta^{\prime}
$$

Integrating (A34) from the surface to the top of the planetary boundary layer, $z_{i}$, yields

$$
\left.\nabla_{2 \mathrm{D}} p^{\prime}\right|_{z_{i}}=\left.\nabla_{2 \mathrm{D}} p^{\prime}\right|_{z=0}+g \int_{0}^{z_{i}} \frac{\nabla_{2 \mathrm{D}} \theta^{\prime}}{\alpha_{0} \theta_{0}} .
$$

This equation can be written as

$$
\left.\nabla_{2 \mathrm{D}} p^{\prime}\right|_{z_{i}}=\left.\nabla_{2 \mathrm{D}} p^{\prime}\right|_{z=0}+\frac{g z_{i}}{\alpha_{0} \theta_{0}} \nabla_{2 \mathrm{D}} \theta^{\prime}
$$

if the planetary boundary layer is assumed to be well mixed in $\theta$, as shown in Figure 3.

Since the intensity of local wind circulations is directly affected by the magnitude of the horizontal pressure gradient (i.e., $\left.\partial \vec{V} / \partial t \sim-(1 / \rho) \nabla_{2 \mathrm{D}} p^{\prime}\right)$, the local wind circulations are also directly a function of $z_{i} \nabla_{2 \mathrm{D}} \theta^{\prime}$. Furthermore, if (A35) is differentiated with respect to time, 
$\left.\frac{\partial}{\partial t} \nabla_{z} p^{\prime}\right|_{z_{i}}=\left.\frac{\partial}{\partial t} \nabla_{2 \mathrm{D}} p^{\prime}\right|_{z=0}+\frac{g}{\alpha_{0} \theta_{0}}\left\{\theta^{\prime} \nabla_{2 \mathrm{D}} \frac{\partial z_{i}}{\partial t}+z_{i} \nabla_{2 \mathrm{D}} \frac{\partial \theta^{\prime}}{\partial t}\right\}$.

Since $\partial z_{i} / \partial t$ is proportional to the surface heat flux from (4a) and $\partial \theta^{\prime} / \partial t$ is proportional to the surface diabatic heating, the relationship of the local wind circulations to horizontal variations in the surface heat flux, $H$, is demonstrated.

A more quantitative examination of the importance of these local wind circulations is presented by Dalu et al. [1996]. The equations used by them can be written as

$$
\begin{gathered}
\left(\frac{\partial}{\partial t}+\lambda\right) u+U \frac{\partial u}{\partial x}+f v-\frac{1}{\rho_{0}} \frac{\partial p}{\partial x}-K \frac{\partial^{2} u}{\partial x^{2}}=0 \\
\left(\frac{\partial}{\partial t}+\lambda\right) v+U \frac{\partial y}{\partial x}+f u-K \frac{\partial^{2} u}{\partial x^{2}}=0 \\
\left(\frac{\partial}{\partial t}+\lambda\right) w+U \frac{\partial w}{\partial x}+\frac{1}{\rho_{0}} \frac{\partial p}{\partial z}-g \frac{\theta^{\prime}}{\theta_{0}}-K \frac{\partial^{2} w}{\partial x^{2}}=0 \\
\left(\frac{\partial}{\partial t}+\lambda\right) \theta^{\prime}+U \frac{\partial \theta^{\prime}}{\partial x}+w \frac{\partial \theta^{\prime}}{\partial x}-K \frac{\partial^{2} \theta^{\prime}}{\partial x^{2}}-Q=0
\end{gathered}
$$

where $\lambda$ is a long wavelength damping coefficient which is based on observations ( $\lambda=10^{-4}$ is used) [Haurwitz, 1947]. $K$ is the horizontal turbulent exchange coefficient, and $Q$ is the diabatic heating between $z=0$ and $z=z_{i}$.

This set of equations can be solved as a function of the spatial scale of heating $L_{x}$, the depth of the boundary layer $z_{i}$, and the magnitude of the heating, $H . L_{x}$ can be obtained from $\nabla_{2 \mathrm{D}} H$, since this gradient can be represented as the sensible heat flux divided by a length scale. Figure 3 of Dalu et al. [1996] illustrates the relative importance of turbulent heating of the planetary boundary layer relative to heating and cooling resulting from the local wind circulation for several horizontal spatial scales of surface heating, large-scale wind speed, and intensity of horizontal turbulent mixing. Over a period of daytime heating, the local wind circulation produces heating associated with sinking motion and cooling associated with rising air, associated with adiabatic compression and expansion, respectively. Landscape variations have their largest influence on generating local wind circulations for horizontal spatial scales of the order of the Rossby radius $R_{0}$, defined as

$$
R_{0}=z_{i} N /\left(f^{2}+\lambda^{2}\right)
$$

where $\left.N=\left[\left(g / \theta_{0}\right)(\partial \theta / \partial z)\right)\right]^{1 / 2}, f$ is the Coriolis parameter, and $2 \Omega \sin \phi(\omega=2 \pi /$ day $) ; \phi$ is the latitude. For typical values $\left(z_{i}=1 \mathrm{~km} ; \partial \theta_{0} / \partial z=1^{\circ} \mathrm{C} 100 \mathrm{~m}^{-1} ; f=\right.$ $\left.10^{-4} \mathrm{~s}^{-1} ; \lambda=10^{-4} \mathrm{~s}^{-1}\right), R_{0} \cong 90 \mathrm{~km}$.

Zeng and Pielke [1993, 1995a, 1995b] and Avissar and Chen [1993] have applied nonlinear numerical modeling of idealized landscape patterns to explore how the Dalu et al. [1996] type conclusions are affected by nonlinear effects. Chen and Avissar [1994a], using a nonlinear model, found, in support of the Dalu et al. results, that the strongest mesoscale heat fluxes occurred when the surface wavelength of heating was close to $R_{0}$.

\section{ACKNOWLEDGMENTS.}

The author acknowledges support from NASA grant NAG8-1511, NSF grant DEB-9632852, EPA grant R824993-01-0, and Tulane University contract TUL062-98/99. I thank Dallas Staley for preparation of the manuscript.

James Smith was the Editor responsible for this paper. He thanks two anonymous technical reviewers and Lamont Poole for the cross-disciplinary review.

\section{REFERENCES}

Adegoke, J. O., Satellite based investigation of land surfaceclimate interactions in the United States midwest, Ph.D. dissertation, 162 pp., Dep. of Geogr., Pa. State Univ., University Park, 2000.

Amiro, B. D., J. I. MacPherson, and R. L. Desjardins, BOREAS flight measurements of forest-fire effects on carbon dioxide and energy fluxes, Agric. For. Meteorol., 96, 199-208, 1999.

Anthes, R. A., Enhancement of convective precipitation by mesoscale variations in vegetative covering in semiarid regions, J. Clim. Appl. Meteorol., 23, 541-554, 1984.

Arya, S. P., Introduction to Micrometeorology, 307 pp., Academic, San Diego, Calif., 1988.

Avissar, R., and F. Chen, Development and analysis of prognostic equations for mesoscale kinetic energy and mesoscale (subgrid scale) fluxes for large-scale atmospheric models, J. Atmos. Sci., 50, 3751-3774, 1993.

Avissar, R., and Y. Liu, Three-dimensional numerical study of shallow convective clouds and precipitation induced by land surface forcing, J. Geophys. Res., 101, 7499-7518, 1996.

Avissar, R., and R. A. Pielke, A parameterization of heterogeneous land surfaces for atmospheric numerical models and its impact on regional meteorology, Mon. Weather Rev., 117, 2113-2136, 1989.

Avissar, R., and T. Schmidt, An evaluation of the scale at which ground-surface heat flux patchiness affects the convective boundary layer using large-eddy simulations, J. Atmos. Sci., 55, 2666-2689, 1998.

Baker, R. D., B. H. Lynn, A. Boone, W.-K. Tao, and J. Simpson, The influence of soil moisture, coastline curvature, and land-breeze circulations on sea-breeze initiated precipitation, J. Hydrometeorol., in press, 2001.

Barnston, S. G., and P. T. Schickedanz, The effect of irrigation on warm season precipitation in the southern Great Plains, J. Clim. Appl. Meteorol., 23, 865-888, 1984.

Baron, J. S., M. D. Hartman, T. G. F. Kittel, L. E. Band, D. S. Ojima, and R. B. Lammers, Effects of land cover, water redistribution, and temperature on ecosystem processes in the South Platte basin, Ecol. Appl., 8, 1037-1051, 1998.

Betts, A. K., R. L. Desjardins, and J. I. MacPherson, Budget analysis of the boundary layer grid flights during FIFE 1987, J. Geophys. Res., 18, 18,533-18,546, 1992.

Betts, R. A., J. H. Ball, A. C. M. Beljaars, M. J. Miller, and P. Viterbo, The land-surface-atmosphere interaction: A re- 
view based on observational and global modeling perspectives, J. Geophys. Res., 101, 7209-7225, 1996.

Betts, R. A., P. M. Cox, S. E. Lee, and F. I. Woodward, Contrasting physiological and structural vegetation feedbacks in climate change simulations, Nature, 387, 796-799, 1997.

Bohren, C. F., and B. A. Albrecht, Atmospheric Thermodynamics, 416 pp., Oxford Univ. Press, New York, 1998.

Bonan, G. B., Effects of land use on the climate of the United States, Clim. Change, 37, 449-486, 1997.

Bosilovich, M. G., and W.-Y. Sun, Numerical simulation of the 1993 midwestern flood: Land-atmosphere interactions, J. Clim., 12, 1490-1505, 1999.

Broström, A., M. Coe, S. P. Harrison, R. Gallimore, J. E. Kutzbach, J. Foley, I. C. Prentice, and P. Behling, Land surface feedbacks and paleomonsoons in northern Africa, Geophys. Res. Lett., 25, 3615-3618, 1998.

Brubaker, K. L., and D. Entekhabi, An analytic approach to modeling land-atmosphere interaction, 1, Construct and equilibrium behavior, Water Resour. Res., 31, 619-632, 1995.

Brubaker, K. L., D. Entekhabi, and P. S. Eagleson, Estimation of continental precipitation recycling, J. Clim., 6, 10771089, 1993

Bryant, N. A., L. F. Johnson, A. J. Brazel, R. C. Balling, C. F. Hutchinson, and L. R. Beck, Measuring the effect of overgrazing in the Sonoran Desert, Clim. Change, 17, 243-264, 1990.

Burke, E. J., W. J. Shuttleworth, and Z.-L. Yang, Heterogeneous vegetation affects GCM-modeled climate, GEWEX WCRP News, 10, 7-8, 2000.

Carleton, A. M., D. Travis, D. Arnold, R. Brinegar, D. E. Jelinski, and D. R. Easterling, Climatic-scale vegetationcloud interactions during drought using satellite data, Int. J. Climatol., 14, 593-623, 1994.

Chang, J. T., and P. J. Wetzel, Effects of spatial variations of soil moisture and vegetation on the evolution of a prestorm environment: A case study, Mon. Weather Rev., 119, 13681390, 1991.

Chase, T. N., R. A. Pielke, T. G. F. Kittel, R. Nemani, and S. W. Running, The sensitivity of a general circulation model to global changes in leaf area index, J. Geophys. Res., 101, 7393-7408, 1996.

Chase, T. N., R. A. Pielke Sr., T. G. F. Kittel, J. S. Baron, and T. J. Stohlgren, Potential impacts on Colorado Rocky Mountain weather due to land use changes on the adjacent Great Plains, J. Geophys. Res., 104, 16,673-16,690, 1999.

Chase, T. N., R. A. Pielke, T. G. F. Kittel, R. R. Nemani, and S. W. Running, Simulated impacts of historical land cover changes on global climate, Clim. Dyn., 16, 93-105, 2000.

Chen, F., and R. Avissar, The impact of land-surface wetness heterogeneity on mesoscale heat fluxes, J. Appl. Meteorol., 33, 1323-1340, 1994a.

Chen, F., and R. Avissar, Impact of land-surface moisture variabilities on local shallow convective cumulus and precipitation in large-scale models, J. Appl. Meteorol., 33, 13821394, 1994b.

Clark, C. A., and R. W. Arritt, Numerical simulations of the effect of soil moisture and vegetation cover on the development of deep convection, J. Appl. Meteorol., 34, 20292045, 1995.

Claussen, M., Modeling bio-geophysical feedback in the Sahel, Rep. 163, 26 pp., Max Planck Inst. for Meteorol., Hamburg, Germany, 1995.

Claussen, M., On multiple solutions of the atmosphere-vegetation system in present-day climate, Global Change Biol., 4, $549-560,1998$.

Copeland, J. H., R. A. Pielke, and T. G. F. Kittel, Potential climatic impacts of vegetation change: A regional modeling study, J. Geophys. Res., 101, 7409-7418, 1996.

Costa, M. H., and J. A. Foley, Combined effects of deforestation and doubled atmospheric $\mathrm{CO}_{2}$ concentrations on the climate of Amazonia, J. Clim., 13, 35-58, 2000.

Cotton, W. R., Storms, Geophys. Sci. Ser., vol. 1, 158 pp., ASTeR Press, Fort Collins, Colo., 1990.

Cotton, W. R., and R. A. Anthes, Storm and Cloud Dynamics, Int. Geophys. Ser., vol. 44, 883 pp., Academic, San Diego, Calif., 1989.

Crook, N. A., Sensitivity of moist convection forced by boundary layer processes to low-level thermodynamic fields, Mon. Weather Rev., 124, 1767-1785, 1996.

Cutrim, E., D. W. Martin, and R. M. Rabin, Enhancement of cumulus clouds over deforested lands in Amazonia, Bull. Am. Meteorol. Soc., 76, 1801-1805, 1995.

Dalu, G. A., R. A. Pielke, M. Baldi, and X. Zeng, Heat and momentum fluxes induced by thermal inhomogeneities, $J$. Atmos. Sci., 53, 3286-3302, 1996.

Deardorff, J. W., Three-dimensional numerical study of the height and mean structure of a heated planetary boundary layer, Boundary Layer Meteorol., 7, 81-106, 1974.

Delworth, T., and S. Manabe, The influence of soil wetness on near-surface atmospheric variability, J. Clim., 2, 1447-1462, 1989.

De Ridder, K., Land surface processes and the potential for convective precipitation, J. Geophys. Res., 102, 30,085-30,090, 1997.

De Ridder, K., The impact of vegetation cover on Sahelian drought persistence, Boundary Layer Meteorol., 88, 307-321, 1998.

De Ridder, K., and H. Gallée, Land surface-induced regional climate change in southern Israel, J. Appl. Meteorol., 37, 1470-1485, 1998.

Dirmeyer, P. A., Vegetation stress as a feedback mechanism in midlatitude drought, J. Clim., 7, 1463-1483, 1994.

Dirmeyer, P. A., Assessing GCM sensitivity to soil wetness using GSWP data, J. Meteorol. Soc. Jpn., 77, 1-19, 1999.

Dirmeyer, P. A., and J. Shukla, The effect on regional and global climate of expansion of the world's deserts, $Q . J$. R. Meteorol. Soc., 122, 451-482, 1996.

Dirmeyer, P. A., and F. J. Zeng, Precipitation infiltration in the simplified SiB land surface scheme, J. Meteorol. Soc. Jpn., 77, 1-13, 1999.

Doran, J. S., and S. Zhong, A study of the effects of sub-gridscale land use differences on atmospheric stability in prestorm environments, J. Geophys. Res., 105, 9381-9392, 2000.

Eastman, J. L., M. B. Coughenour, and R. A. Pielke, The effects of $\mathrm{CO}_{2}$ and landscape change using a coupled plant and meteorological model, Global Change Biol., in press, 2001.

Eltahir, E. A. B., Role of vegetation in sustaining large-scale atmospheric circulations in the tropics, J. Geophys. Res., 101, 4255-4268, 1996.

Eltahir, E. A. B., and R. L. Bras, Precipitation recycling in the Amazon basin, Q. J. R. Meteorol. Soc., 120, 861-880, 1994.

Eltahir, E. A. B., and J. S. Pal, Relationship between surface conditions and subsequent rainfall in convective storms, $J$. Geophys. Res., 101, 26,237-26,245, 1996.

Emori, S., The interaction of cumulus convection with soil moisture distribution: An idealized simulation, J. Geophys. Res., 103, 8873-8884, 1998.

Entekhabi, D., and D. L. Brubaker, An analytic approach in modeling land-atmosphere interaction, 2, Stochastic extension, Water Resour. Res., 31, 633-643, 1995.

Entekhabi, D., I. Rodriguez-Iturbe, and R. L. Bras, Variability in large-scale water balance with land surface-atmosphere interaction, J. Clim., 5, 798-813, 1992.

Fast, J. D., and M. D. McCorcle, The effect of heterogeneous 
soil moisture on a summer baroclinic circulation in the central United States, Mon. Weather Rev., 119, 2140-2167, 1991.

Fennessy, M. J., and J. Shukla, Impact of initial soil wetness on seasonal atmospheric prediction, J. Clim., 12, 3167-3180, 1999.

Ferranti, L., and F. Molteni, Ensemble simulations of Eurasian snow-depth anomalies and their influence on the summer Asian monsoon, Q. J. R. Meteorol. Soc., 125, 2597-2610, 1999.

Fitzjarrald, D. R., O. C. Acevedo, and K. E. Moore, Climatic consequences of leaf presence in the eastern United States, J. Clim., 14, 598-614, 2001.

Foley, J., J. E. Kutzbach, M. T. Coe, and S. Lewis, Feedbacks between climate and boreal forests during the Holocene epoch, Nature, 371, 52-54, 1994.

Foley, J. A., S. Levis, I. Prentice, D. Colin-Pollard, and S. L. Thompson, Coupling dynamic models of climate and vegetation, Global Change Biol., 4, 561-579, 1998.

Fraedrich, K., A. Kleidon, and F. Lunkeit, A green planet versus a desert world: Estimating the effect of vegetation extremes on the atmosphere, J. Clim., 12, 3156-3163, 1999.

Ganopólsik, A., C. Kubatzki, M. Claussen, V. Brovkin, and V. Petoukhov, The influence of vegetation-atmosphere-ocean interaction on climate during the mid-Holocene, Science, 280, 1916-1919, 1998.

Garratt, J. R., The Atmospheric Boundary Layer, Cambridge Atmos. and Space Sci. Ser., 316 pp., Cambridge Univ. Press, New York, 1992.

Garrett, A. J., A parameter study of interactions between convective clouds, the convective boundary layer, and forested surface, Mon. Weather Rev., 110, 1041-1059, 1982.

Garstang, M., and D. R. Fitzjarrald, Observations of surface to atmosphere interactions in the tropics, 405 pp., Oxford Univ. Press, New York, 1999.

Giambelluca, T. W., J. Fox, S. Yarnasarn, P. Onibutr, and M. A. Nullet, Dry-season radiation balance of land covers replacing forest in northern Thailand, Agric. For. Meteorol., 95, 53-65, 1999.

Glantz, M. H., R. W. Katz, and N. Nicholls (Eds.), Teleconnections Linking Worldwide Climate Anomalies, Cambridge Univ. Press, New York, 1991.

Goutorbe, J.-P., et al., HAPEX-Sahel: A large-scale study of land-atmosphere interactions in the semi-arid tropics, Ann. Géophys., 12, 53-64, 1994.

Grasso, L., Numerical simulation of the May 15 and April 26, 1991, tornadic thunderstorms, Ph.D. dissertation, $151 \mathrm{pp}$., Dep. of Atmos. Sci., Colo. State Univ., Fort Collins, 1996.

Grasso, L. D., The numerical simulation of dryline formation on soil moisture, Mon. Weather Rev., 128, 2816-2834, 2000.

Hadfield, M. G., W. R. Cotton, and R. A. Pielke, Large-eddy simulations of thermally forced circulations in the convective boundary layer, part I, A small-scale circulation with zero wind, Boundary Layer Meteorol., 57, 79-114, 1991.

Haurwitz, B., Comments on the sea-breeze circulation, J. $\mathrm{Me}$ teorol., 4, 1-8, 1947.

Hayden, B. P., Ecosystem feedbacks on climate at the landscape scale, Philos. Trans. R. Soc. London, Ser. B, 353, 5-18, 1998.

Hoffman, W. A., and R. B. Jackson, Vegetation-climate feedbacks in the conversion of tropical savanna to grassland, J. Clim., 13, 1593-1602, 2000.

Holtslag, A. A. M., and P. G. Duynkerke, Clear and Cloudy Boundary Layers, 372 pp., R. Neth. Acad. of Arts and Sci., Amsterdam, 1998.

Hong, X., M. J. Leach, and S. Raman, A sensitivity study of convective cloud formation by vegetation forcing with different atmospheric conditions, J. Appl. Meteorol., 34, 20082028, 1995.
Hou, A. Y., Hadley circulation as a modulator of the extratropical climate, J. Atmos. Sci., 55, 2437-2457, 1998.

Houze, R. A., Jr., Cloud Dynamics, 573 pp., Academic, San Diego, Calif., 1993.

Huang, X., T. J. Lyons, and R. C. G. Smith, Meteorological impact of replacing native perennial vegetation with annual agricultural species, in Scale Issues in Hydrological Modelling, edited by J. D. Kalma and M. Sivapalan, pp. 401-410, Advanstar Commun., Chichester, England, 1995.

Huang, J., H. M. van den Dool, and K. P. Georgakakos, Analysis of model-calculated soil moisture over the United States (1931-1993) and applications to long-range temperature forecasts, J. Clim., 9, 1350-1362, 1996.

Idso, S., R. Jackson, R. Reginato, B. Kimball, and F. Nakayama, The dependence of bare-soil albedo on soil water content, J. Appl. Meteorol., 14, 109-113, 1975.

Iribarne, J. V., and W. L. Godson, Atmospheric Thermodynamics, 222 pp., D. Reidel, Norwell, Mass., 1974.

Jones, A. S., I. C. Guch, and T. H. Vonder Haar, Data assimilation of satellite-derived heating rates as proxy surface wetness data into a regional atmospheric mesoscale model, part II, A case study, Mon. Weather Rev., 126, 646-667, 1998.

Kanae, S., T. Oki, and K. Musiake, Game-tropics studies on deforestation effects in Indochina, GEWEX News, 9, 1, 4, 1994.

Keenan, T., et al., BMRC Res. Rep. 44, 61 pp., Sci. Plan, Mar. Continent Thunderstorm Exp. (MCTEX), Bur. of Meteorol., Melbourne, Vict., Australia, 1994.

Kiang, J. E., and E. A. B. Eltahir, Role of ecosystem dynamics in biosphere-atmosphere interaction over the coastal region of West Africa, J. Geophys. Res., 104, 31,173-31,189, 1999.

Kleidon, A., and M. Heimann, Assessing the role of deep rooted vegetation in the climate system with model simulations: Mechanism, comparison to observations and implications for Amazonian deforestation, Clim. Dyn., 16, 183199, 2000.

Kleidon, A., K. Fraedrich, and M. Heimann, A green planet versus a desert world: Estimating the maximum effect of vegetation on the land surface climate, Clim. Change, 44, 471-493, 2000.

Koster, R. D., M. J. Suarez, and M. Heiser, Variance and predictability of precipitation at seasonal-to-interannual timescales, J. Hydrometeorol., 1, 26-46, 2000.

Lanicci, J. M., T. N. Carlson, and T. T. Warner, Sensitivity of the Great Plains severe-storm environment to soil-moisture distribution, Mon. Weather Rev., 115, 2660-2673, 1987.

Leemans, R., Land-use change and the terrestrial carbon cycle, Int. Geosphere-Biosphere Programme Global Change Newsl., 37, 24-26, 1999.

Li, B., and R. Avissar, The impact of spatial variability of land-surface heat fluxes, J. Clim., 7, 527-537, 1994.

Li, D., H. Komiyama, K. Kurihara, and Y. Sato, Case studies of the impact of landscape changes on weather modification in western Australia in summer, J. Geophys. Res., 105, 12,30312,315, 2000.

Liu, Y., and R. Avissar, A study of persistence in the landatmosphere system using a general circulation model and observations, J. Clim., 12, 2139-2153, 1999a.

Liu, Y., and R. Avissar, A study of persistence in the landatmosphere system with a fourth-order analytical model, J. Clim., 12, 2154-2168, 1999b.

Liu, Y., C. P. Weaver, and R. Avissar, Toward a parameterization of mesoscale fluxes and moist convection induced by landscape heterogeneity, J. Geophys. Res., 104, 19,51519,553, 1999.

Lu, L., R. A. Pielke, G. E. Liston, W. J. Parton, D. Ojima, and M. Hartman, Implementation of a two-way interactive at- 
mospheric and ecological model and its application to the central United States, J. Clim., 14, 900-919, 2001.

Lynn, B. H., D. Rind, and R. Avissar, The importance of mesoscale circulations generated by subgrid-scale landscape heterogeneities in general circulation models, J. Clim., 8, 191-205, 1995a.

Lynn, B. H., F. Abramopoulos, and R. Avissar, Using similarity theory to parameterize mesoscale heat fluxes generated by sub-grid-scale landscape discontinuities in GCMs, J. Clim., 8, 932-951, 1995b.

Lynn, B. H., W.-K. Tao, and P. J. Wetzel, A study of landscapegenerated deep moist convection, Mon. Weather Rev., 126, 828-942, 1998.

Lyons, T. J., P. Schwerdtfeger, J. M. Hacker, I. J. Foster, R. C. G. Smith, and H. Xinmei, Land-atmosphere interaction in a semiarid region: The bunny fence experiment, Bull. Am. Meteorol. Soc., 74, 1327-1334, 1993.

Lyons, T. J., R. C. G. Smith, and H. Xinmei, The impact of clearing for agriculture on the surface energy budget, Int. J. Climatol., 16, 551-558, 1996.

Lyons, W. A., Lightning, in Storms, Hazard and Disaster Ser., edited by R. A. Pielke Sr. and R. A. Pielke Jr., pp. 60-79, Routledge, New York, 1999.

Mahfouf, J.-F., E. Richard, and P. Mascart, The influence of soil and vegetation on the development of mesoscale circulations, J. Clim. Appl. Meteorol., 26, 1483-1495, 1987.

Mahrt, L., J. S. Sun, D. Vickers, J. I. MacPherson, J. R. Pederson, and R. L. Desjardins, Observations of fluxes and inland breezes over a heterogeneous surface, J. Atmos. Sci., 51, 2484-2499, 1994.

McNider, R. T., and F. J. Kopp, Specification of the scale and magnitude of thermals used to initiate convection in cloud models, J. Appl. Meteorol., 29, 99-104, 1990.

Milly, P. C. D., and K. A. Dunne, Sensitivity of the global water cycle to the water-holding capacity of land, J. Clim., 7, 506-526, 1994

Mölders, N., On the effects of different flooding stages of the Oder and different land-use types on the distributions of evapotranspiration, cloudiness and rainfall in the Brandenburg-Polish border area, Contrib. Atmos. Phys., 72, 1-25, 1999.

Namias, J., Multiple causes of the North American abnormal winter 1976-77, Mon. Weather Rev., 106, 279-295, 1978.

Nemani, R. R., S. W. Running, R. A. Pielke, and T. N. Chase, Global vegetation cover changes from coarse resolution satellite data, J. Geophys. Res., 101, 7157-7162, 1996.

Neumann, J., and Y. Mahrer, A theoretical study of the sea and land breezes of circular islands, J. Atmos. Sci., 31, 2027-2039, 1974.

Nicholson, S., Land surface processes and Sahel climate, Rev. Geophys., 38, 117-139, 2000.

O'Brien, K. L., Sacrificing the Forest: Environmental and Social Struggles in Chiapas, 201 pp., Westview, Boulder, Colo., 1997.

O'Brien, K. L., Upscaling tropical deforestation: Implications for climate change, Clim. Change, 44, 311-329, 2000.

Oke, T. R., Boundary Layer Climates, 435 pp., Methuen, New York, 1987.

Ookouchi, Y., M. Segal, R. C. Kessler, and R. A. Pielke, Evaluation of soil moisture effects on the generation and modification of mesoscale circulations, Mon. Weather Rev., 112, 2281-2292, 1984.

Pan, Z., M. Segal, R. Turner, and E. Takle, Model simulation of impacts of transient surface wetness on summer rainfall in the United States midwest during drought and flood years, Mon. Weather Rev., 123, 1575-1581, 1995.

Pan, Z., E. Takle, M. Segal, and R. Turner, Influences of model parameterization schemes on the response of rainfall to soil moisture in the central United States, Mon. Weather Rev., 124, 1786-1802, 1996.

Pielke, R. A., A three-dimensional numerical model of the sea breezes over south Florida, Mon. Weather Rev., 102, 115139, 1974

Pielke, R. A., Mesoscale Meteorological Modeling, 612 pp., Academic, San Diego, Calif., 1984.

Pielke, R. A., Climate prediction as an initial value problem, Bull. Am. Meteorol. Soc., 79, 2743-2746, 1998.

Pielke, R. A., and R. Avissar, Influence of landscape structure on local and regional climate, Landscape Ecol., 4, 133-155, 1990.

Pielke, R. A., Jr., and R. A. Pielke Sr. (Eds.), Storms, Hazard and Disaster Ser., 960 pp., Routledge, New York, 1999.

Pielke, R. A., and M. Segal, Mesoscale circulations forced by differential terrain heating, in Mesoscale Meteorology and Forecasting, edited by P. Ray, chap. 22, pp. 516-548, Am. Meteorol. Soc., Boston, Mass., 1986.

Pielke, R. A., and X. Zeng, Influence on severe storm development of irrigated land, Natl. Weather Dig., 14, 16-17, 1989.

Pielke, R. A., G. Dalu, J. S. Snook, T. J. Lee, and T. G. F. Kittel, Nonlinear influence of mesoscale land use on weather and climate, J. Clim., 4, 1053-1069, 1991 a.

Pielke, R. A., A. Song, P. J. Michaels, W. A. Lyons, and R. W. Arritt, The predictability of sea-breeze generated thunderstorms, Atmosfera, 4, 65-78, 1991b.

Pielke, R. A., T. J. Lee, J. H. Copeland, J. L. Eastman, C. L. Ziegler, and C. A. Finley, Use of USGS-provided data to improve weather and climate simulations, Ecol. Appl., 7, 3-21, 1997.

Pielke, R. A., G. E. Liston, J. L. Eastman, L. Lu, and M. Coughenour, Seasonal weather prediction as an initial value problem, J. Geophys. Res., 104, 19,463-19,479, 1999a.

Pielke, R. A., R. L. Walko, L. T. Steyaert, P. L. Vidale, G. E. Liston, W. A. Lyons, and T. N. Chase, The influence of anthropogenic landscape changes on weather in south Florida, Mon. Weather Rev., 127, 1663-1673, 1999b.

Pitman, A. J., and M. Zhao, The relative impact of observed change in land cover and carbon dioxide as simulated by a climate model, Geophys. Res. Lett., 27, 1267-1270, 2000.

Pitman, A., R. Pielke, R. Avissar, M. Claussen, J. Gash, and H. Dolman, The role of the land surface in weather and climate: Does the land surface matter?, Int. GeosphereBiosphere Programme Newsl., 39, 4-11, 1999.

Porporato, A., P. D’Odorico, L. Ridolfi, and I. RodriguezIturbe, A spatial model for soil-atmosphere interaction: Model construction and linear stability analysis, J. Hydrometeorol., 1, 61-74, 2000.

Rabin, R. M., and D. W. Martin, Satellite observations of shallow cumulus coverage over the central United States: An exploration of land use impact on cloud cover, J. Geophys. Res., 101, 7149-7155, 1996.

Rabin, R. M., S. Stadler, P. J. Wetzel, D. J. Stensrud, and M. Gregory, Observed effects of landscape variability on convective clouds, Bull. Am. Meteorol. Soc., 71, 272-280, 1990.

Ramírez, J. A., and S. Senareth, A statistical-dynamical parameterization of canopy interception and land surface-atmosphere interactions, J. Clim., 13, 4050-4063, 2000.

Riehl, H., and J. S. Malkus, On the heat balance in the equatorial trough zone, Geophysica, 6, 504-537, 1958.

Riehl, H., and J. M. Simpson, The heat balance of the equatorial trough zone, revisited, Contrib. Atmos. Phys., 52, 287, 1979.

Rodriguez-Iturbe, I., D. Entekhabi, and R. L. Bras, Nonlinear dynamics of soil moisture at climate scales, 1, Stochastic analysis, Water Resour. Res., 27, 1899-1906, 1991a.

Rodriguez-Iturbe, I., D. Entekhabi, J.-S. Lee, and R. L. Bras, 
Nonlinear dynamics of soil moisture at climate scales, 2, Chaotic analysis, Water Resour. Res., 27, 1907-1915, 1991b.

Rosenfeld, J., Sentinels in the sky, Weatherwise, 53, 24-29, 2000.

Schär, C., D. Lüthi, U. Beyerle, and E. Heise, The soil-precipitation feedback: A process study with a regional climate model, J. Clim., 12, 722-741, 1999.

Schrieber, K., R. Stull, and Q. Zhang, Distributions of surfacelayer buoyancy versus lifting condensation level over a heterogenous land surface, J. Atmos. Sci., 53, 1086-1107, 1996.

Schwartz, M. D., Monitoring global change with phenology: The case of the spring green wave, Int. J. Biometeorol., 38, 18-22, 1994.

Segal, M., and R. W. Arritt, Non-classical mesoscale circulations caused by surface sensible heat-flux gradients, Bull. Am. Meteorol. Soc., 73, 1593-1604, 1992.

Segal, M., R. Avissar, M. C. McCumber, and R. A. Pielke, Evaluation of vegetation effects on the generation and modification of mesoscale circulations, J. Atmos. Sci., 45, 2268-2292, 1988.

Segal, M., J. R. Garratt, G. Kallos, and R. A. Pielke, The impact of wet soil and canopy temperatures on daytime boundary-layer growth, J. Atmos. Sci., 46, 3673-3684, 1989.

Segal, M., R. W. Arritt, C. Clark, R. Rabin, and J. Brown, Scaling evaluation of the effect of surface characteristics on potential for deep convection over uniform terrain, Mon. Weather Rev., 123, 383-400, 1995.

Segal, M., R. W. Arritt, J. Shen, C. Anderson, and M. Leuthold, On the clearing of cumulus clouds downwind from lakes, Mon. Weather Rev., 125, 639-646, 1997.

Segal, M., Z. Pan, R. W. Turner, and E. S. Takle, On the potential impact of irrigated areas in North American summer rainfall caused by large-scale systems, J. Appl. Meteorol., 37, 325-331, 1998.

Seth, A., and F. Giorgi, The effects of domain choice on summer precipitation simulations and sensitivity in a regional climate model, J. Clim., 11, 2698-2712, 1998.

Shabbar, A., B. Bonsal, and M. Khandekar, Canadian precipitation patterns associated with the Southern Oscillation, J. Clim., 10, 3016-3027, 1997.

Shaw, B. L., R. A. Pielke, and C. L. Ziegler, A three-dimensional numerical simulation of a Great Plains dryline, Mon. Weather Rev., 125, 1489-1506, 1997.

Shen, S., and M. Y. Leclerc, How large must surface inhomogeneities be before they influence the convective boundary layer structure? A case study, Q. J. R. Meteorol. Soc., 121, 1209-1228, 1995.

Shinoda, M., and M. Gamo, Interannual variations of boundary layer temperature over the African Sahel associated with vegetation and the upper troposphere, J. Geophys. Res., 105, 12,317-12,327, 2000.

Simpson, J. E., Sea Breeze and Local Winds, 234 pp., Cambridge Univ. Press, New York, 1994.

Simpson, J., N. E. Westcott, R. J. Clerman, and R. A. Pielke, On cumulus mergers, Arch. Meteorol. Geophys. Bioklimatol., Ser. A, 29, 1-40, 1980.

Simpson, J., T. D. Keenan, B. Ferrier, R. H. Simpson, and G. J. Holland, Cumulus mergers in the maritime continent region, Meteorol. Atmos. Phys., 51, 73-99, 1993.

Sorbjan, Z., Structure of the Atmospheric Boundary Layer, 317 pp., Prentice-Hall, Englewood Cliffs, N. J., 1989.

Souza, E. P., N. O. Rennó, and M. A. F. Silva Dias, Convective circulations induced by surface heterogeneities, J. Atmos. Sci., 57, 2915-2922, 2000.

Stohlgren, T. J., T. N. Chase, R. A. Pielke, T. G. F. Kittel, and J. Baron, Evidence that local land use practices influence regional climate and vegetation patterns in adjacent natural areas, Global Change Biol., 4, 495-504, 1998.
Stull, R. B., An Introduction to Boundary Layer Meteorology, 666 pp., Kluwer Acad., Norwell, Mass., 1988.

Sud, Y. C., W. C. Chao, and G. K. Walker, Dependence of rainfall on vegetation: Theoretical considerations, simulation experiments, observations, and inferences from simulated atmospheric soundings, J. Arid Environ., 25, 5-18, 1993.

Sud, Y. C., K. M. Lau, G. K. Walker, and J. H. Kim, Understanding biosphere-precipitation relationships: Theory, model simulations and logical inferences, Mausam, 46, 1-14, 1995.

Sun, W.-Y., M. G. Bosilovich, and J.-D. Chern, Regional response of the NCAR CCM1 to anomalous surface properties, Terr. Atmos. Oceanic Sci., 8, 271-288, 1997.

Tao, W.-K., S. Lang, W. S. Olson, R. Meneghini, S. Yang, J. Simpson, C. Kummerow, E. Smith, and J. Halverson, Retrieved vertical profiles of latent heat release using TRMM rainfall products, J. Appl. Meteorol., in press, 2001.

Taylor, C. M., F. Saïd, and T. Lebel, Interactions between the land surface and mesoscale rainfall variability during HAPEX-Sahel, Mon. Weather Rev., 125, 2211-2227, 1997.

Taylor, C. M., R. J. Harding, R. A. Pielke Sr., P. L. Vidale, R. L. Walko, and J. W. Pomeroy, Snow breezes in the boreal forest, J. Geophys. Res., 103, 23,087-23,101, 1998.

Texier, D., N. de Noblet, and P. Braconnot, Sensitivity of the African and Asian monsoons to mid-Holocene insolation and data-inferred surface changes, J. Clim., 13, 164-181, 2000.

Trenberth, K. E., Atmospheric moisture recycling: Role of advection and local evaporation, J. Clim., 12, 1368-1381, 1999.

Vidale, P. L., R. A. Pielke, L. T. Steyaert, and A. Barr, Case study modeling of turbulent and mesoscale fluxes over the BOREAS region, J. Geophys. Res., 102, 29,167-29,188, 1997.

Viterbo, P., and A. K. Betts, Impact of the ECMWF reanalysis soil water on forecasts of the July 1993 Mississippi flood, $J$. Geophys. Res., 104, 19,361-19,366, 1999.

Wallace, J. M., and D. S. Gutzler, Teleconnections in the geopotential height field during the Northern Hemisphere winter, 1981, Mon. Weather Rev., 109, 784-812, 1981.

Wallace, J. M., and P. V. Hobbs, Atmospheric Science: An Introductory Survey, 467 pp., Academic, San Diego, Calif., 1977.

Wang, G., and E. A. B. Eltahir, The role of vegetation dynamics in the climate of west Africa, Rep. 344, 224 pp., Dep. of Civ. and Environ. Eng., Mass. Inst. of Technol., Cambridge, Mass., 1999.

Wang, G., and E. A. B. Eltahir, Ecosystem dynamics and the Sahel drought, Geophys. Res. Lett., 27, 795-798, 2000a.

Wang, G., and E. A. B. Eltahir, Biosphere-atmosphere interactions over West Africa, I, Development and validation of a coupled dynamic model, Q. J. R. Meteorol. Soc., 126, 1239-1260, 2000b.

Wang, J., R. L. Bras, and E. A. B. Eltahir, A stochastic linear theory of mesoscale circulation induced by the thermal heterogeneity of the land surface, J. Atmos. Sci., 53, 33493366, 1997.

Wang, J., E. A. B. Eltahir, and R. L. Bras, Numerical simulation of nonlinear mesoscale circulations induced by the thermal heterogeneities of land surface, J. Atmos. Sci., 55, 447-464, 1998.

Wang, J., R. L. Bras, and E. A. B. Eltahir, The impact of observed deforestation on the mesoscale distribution of rainfall and clouds in Amazonia, J. Hydrometeorol., 1, 267286, 2000.

Weaver, C. P., and R. Avissar, Atmospheric disturbances caused by human modification of the landscape, Bull. Am. Meteorol. Soc., 82, 269-282, 2001. 
Weaver, C. P., R. Avissar, and Y. Liu, On the parameterization of convective precipitation generated by land cover change/ land use in large-scale atmospheric models, in Proceedings, 15th Conference on Hydrology, pp. 289-291, Am. Meteorol. Soc., Boston, Mass., 2000.

Wei, H., and C. Fu, Study of the sensitivity of a regional model in response to land cover change over northern China, Hydrol. Process., 12, 2249-2265, 1998.

Wetzel, P. J., S. Argentini, and A. Boone, Role of land surface in controlling daytime cloud amount: Two case studies in the GCIP-SW area, J. Geophys. Res., 101, 7359-7370, 1996.

Wu, Z.-X., and R. E. Newell, Influence of sea surface temperature on air temperature in the tropic, Clim. Dyn., 14, 275-290, 1998.

Xue, Y., The impact of desertification in the Mongolian and the Inner Mongolian grassland on the regional climate, J. Clim., 9, 2173-2189, 1996.

Xue, Y., Biosphere feedback on regional climate in tropical north Africa, Q. J. R. Meteorol. Soc., 123, 1483-1515, 1997.

Xue, Y., and J. Shukla, The influence of land surface properties on Sahel climate, part I, Desertification, J. Clim., 6, 2232-2245, 1993.

Xue, Y., and J. Shukla, The influence of land surface properties on Sahel climate, part II, Afforestation, J. Clim., 9, 3260-3275, 1996.

Xue, Y., M. J. Fennessy, and P. J. Sellers, Impact of vegetation properties on U.S. summer weather prediction, J. Geophys. Res., 101, 7419-7430, 1996.

Zeng, N., and J. D. Neelin, A land-atmosphere interaction theory for the tropical deforestation problem, J. Clim., 12, 857-872, 1999.
Zeng, N., J. D. Neelin, K.-M. Lau, and C. J. Tucker, Enhancement of interdecadal climate variability in the Sahel by vegetation interaction, Science, 286, 1537-1540, 1999.

Zeng, X., and R. A. Pielke, Error-growth dynamics and predictability of surface thermally induced atmospheric flow, $J$. Atmos. Sci., 50, 2817-2844, 1993.

Zeng, X., and R. A. Pielke, Landscape-induced atmospheric flow and its parameterization in large-scale numerical models, J. Clim., 8, 1156-1177, 1995a.

Zeng, X., and R. A. Pielke, Further study on the predictability of landscape-induced atmospheric flow, J. Atmos. Sci., 52, 1680-1698, 1995b.

Zeng, X., Y.-J. Dai, R. E. Dickinson, and M. Shaikh, The role of root distribution for climate simulation over land, Geophys. Res. Lett., 25, 4533-4536, 1998.

Zhao, M., A. J. Pitman, and T. N. Chase, The impact of land cover change on the atmospheric circulation, Clim. Dyn., in press, 2001.

Zhong, S., and J. C. Doran, An evaluation of the importance of surface flux variability on GCM-scale boundary-layer characteristics using realistic meteorological and surface forcing, J. Clim., 11, 2774-2788, 1998.

Ziegler, C. L., T. J. Lee, and R. A. Pielke Sr., Convective initiation at the dryline: A modeling study, Mon. Weather Rev., 125, 1001-1026, 1997.

R. A. Pielke, Department of Atmospheric Science, Colorado State University, Fort Collins, CO 80523-1371. (pielke@snow. atmos.colostate.edu) 
- $178 \bullet$ 